Leticia Bolian Zimback

Quais características influenciam a limitação de dispersão de sementes em uma comunidade arbórea tropical?

Which characteristics influence seed limitation in a tropical tree community?

Versão corrigida

São Paulo 
Leticia Bolian Zimback

\section{Quais características influenciam a limitação de dispersão de sementes em uma comunidade arbórea tropical?}

Which characteristics influence seed limitation in a tropical tree community?

Dissertação apresentada ao Instituto de Biociências da Universidade de São Paulo, para a obtenção de Título de Mestre em Ciências, na Área de Ecologia

Orientadora: Prof $^{\mathrm{a}}$. Dr ${ }^{\mathrm{a}}$. Adriana Maria Zanforlin Martini

Versão corrigida

São Paulo 


\section{Ficha Catalográfica}

\section{Zimback, Leticia}

Quais características influenciam a

limitação de dispersão de sementes emu ma

comunidade arbórea tropical?

78 páginas

Dissertação (Mestrado) - Instituto de Biociências da Universidade de São Paulo.

Departamento de Ecologia.

1. Chuva de semente 2. Coexistência 3. Estruturação de comunidades I. Universidade de São Paulo. Instituto de Biociências. Departamento de Ecologia.

\section{Comissão Julgadora:}




\section{Dedicatória}

Aos meus pais,

Douglas e Vartuy, que são apaixonados por tudo o que eu faço. 


\section{Epígrafe}

Blackbird singing in the dead of night

Take these broken wings and learn to fly

All your life

You were only waiting for this moment to arise

Blackbird singing in the dead of night

Take these sunken eyes and learn to see

All your life

You were only waiting for this moment to be free 


\section{Agradecimentos}

Gostaria de agradecer à todos que participaram direta ou indiretamente da realização do meu trabalho. Agradeço aos meus pais que sempre me apoiam em todas as maluquices que eu invento e sempre acham tudo lindo. Vartuy e Douglas, vocês são demais!! Agradeço muito a Deus por ser filha de vocês. Meus exemplos, meus companheiros, meus amigos, meus amores, meu tudo! Obrigada, obrigada, obrigada!! Quero agradecer também ao Gui, meu lindão!! Por estar sempre por perto e por fazer comidinhas gostosas nessa fase louca do final do mestrado. Te amo!!

Quero agradecer a minha orientadora Adriana Martini, por todo o conhecimento, dedicação, força de vontade, garra e, principalmente, alegria. Dri, adorei trabalhar com você!! Obrigada por ter me aceitado como sua aluna e por ter me proporcionado tantas experiências e aprendizados nesses quase três anos. Obrigada, querida orientadora. Quem sabe um dia não te levo para os passarinhos (rsrs). Quero agradecer também ao professor Alexandre Adalardo por ser tão solícito e aceitar me ajudar com o refinamento da metodologia do meu estudo. Sou muito grata também pela oportunidade de ser monitora no Curso do R, aprendi muito com você também Alê. Aproveitando que estamos falando do Imperador Soberano do Labtrop, gostaria de agradecer a todos os meus colegas de laboratório (Ju, Bruninho, Lu(ísa), Lu(anne), Renanzito, Bianca, Drielli, Marceleza). Obrigada pelas calorosas discussões de artigo e também pelas outras coisas do universo e tudo mais!! Obrigada, vocês fizeram a experiência do mestrado mais divertida e prazerosa.

Agradeço ao Glauco Machado, Paulo Inácio, Gustavo Requena e Adriana Martini, por me proporcionarem uma experiência acadêmica e pessoal incrível. Ser 
monitora do Curso de Campo foi uma das melhores experiências do mestrado e fico feliz por ter participado do processo de aprendizado de outras pessoas também. Agradeço a meus colegas monitores queridos (Adrianzito, Didi e Puhzinha) que foram sensacionais e que me ensinaram muitas coisas durante esses 26 dias Morando juntos. Obrigada!! Agradeço também aos colegas e à equipe do meu primeiro curso (2015), por terem se dedicado tanto ao nosso aprendizado durante tanto tempo. Podem ter certeza que valeu a pena. Muito obrigada!!

Agradeço também a Prof ${ }^{\mathrm{a}}$. Dr ${ }^{\mathrm{a}}$. Renata Pardini que me deu a oportunidade de ser monitora da sua disciplina "Diversidade e Conservação de Vertebrados na América do Sul". Aprendi muito e pude ter contato com outros assuntos que enriqueceram o desenvolvimento da minha dissertação. Agradeço aos membros do meu Comitê de Acompanhamento (Leandro Freitas, Márcia Marques e Marco Pizo) que contribuíram com ótimas ideias e foram essenciais para o bom desenvolvimento do trabalho. Obrigada!!

Agradeço ao $\mathrm{CNPq}$ pelo auxílio financeiro. Agradeço aos técnicos do Departamento de Ecologia que me ajudaram nas triagens do material coletado (Rai (minha psicóloga querida), Lenilda, Gustavo), nas análises estatísticas dos dados (Melina) e na impressão desse document (Obrigada Luis). Agradeço aos estagiários queridíssimos que me ajudaram em campo (Caio e Eliesse, meus mateiros preferidos) e com a triagem das sementes (Bianca, minha pupila...rs). Agradeço aos pesquisadores do Herbário Dom Bento Pickel (SPSF) que me ajudaram na identificação das sementes com muita boa vontade e alegria. Obrigada Geraldo Franco (Gê), João Batista Baitello e Osni Aguiar. Agradeço imensamente ao amigo Marcos Melo, ornitólogo de primeira, que identificou todas as vocalizações das aves que eu precisei. Muito obrigada por estar sempre disposto a ajudar, te devo umas 
cervejas!! Agradeço ao Marceleza pelas idas a campo. Vamos sentir falta de fazer um cafezinho na paludosa, hein?

Agradeço imensamente a Camila Celestino que me ajudou a organizar as referências e a ser feliz mesmo no meio de tanta loucura do final do mestrado. Obrigada Mila, sua linda!! Pelo mesmo motive agradeço a todos os grandes amigos que o mestrado me trouxe (Bruno Sano, Bruno Travassos, Adriane, Gabriel Pimenta, Paula Puh, Paulinha Moraes, Diana, Danilo, Luísa, Luanne, Adrian, Andrés, Renan, e todos mais que talvez eu tenha esquecido) .

Por fim, agradeço aos colegas da Prefeitura que sempre me incentivaram a entrar no mestrado, estudar e também terminar logo para poder voltar (rs). Obrigada pela compreensão e por toda amizade. Obrigada Anelisa Magalhães, Maria Amélia Carvalho, Juliana Summa, Tiago Ostorero, Sylvia Matsuda, Brígida Fries, Ana Maria Brisch, Linda Lacerda e Érica Blanco. Vocês são demais!!

Muito obrigada a todos!! E muito obrigada a você que está prestes a ler o resultado de um trabalho feito com muito suor, muito aprendizado e com muito amor. Divirta-se e mande sugestões! 


\section{Índice}

I. Resumo

II. Abstract 13

III.Introdução 15

IV. Material e Métodos

1. Área de estudo 22

2. Levantamento das espécies arbóreas 23

3. Chuva de sementes 25

4. Análise de dados

4.1. Variações sazonais na chuva de sementes 26

4.2. Limitação de dispersão espacial e temporal (LDe e LDt) 26

4.3. Relação entre limitação de dispersão espacial e temporal 27

4.4. Características que influenciam a limitação de dispersão espacial e temporal 28

V. Resultados

1. Descrição geral da chuva de sementes 35

2. Relação entre limitação de dispersão espacial e temporal 38

3. Características que influenciam a limitação de dispersão espacial e temporal 38

VI. Discussão 44

VII.Referências Bibliográficas 55

VIII. Anexo 1 66

IX. Anexo 2 70

IX. Anexo 3 73 
X. Anexo 4

75

XI. Anexo 5 


\section{Resumo}

A limitação de dispersão de sementes tem sido empiricamente investigada como um mecanismo equalizador das diferenças competitivas entre espécies que coexistem em comunidades vegetais. Além da limitação espacial, as variações temporais da dispersão também podem ser importantes para a coexistência das espécies. O objetivo do estudo foi verificar a relação entre limitação de dispersão espacial (LDe) e limitação de dispersão temporal (LDt) e as características das espécies que influenciam as duas limitações. Em uma floresta da planície costeira, a chuva de sementes foi amostrada, ao longo de 36 meses, em 40 coletores $\left(20 \mathrm{~m}^{2}\right)$ distantes 100m entre si e da borda do fragmento. A abordagem de seleção de modelos mistos foi utilizada para testar a relação entre a limitação de dispersão e a massa média das sementes, a síndrome de dispersão, a altura máxima local e a frequência de distribuição dos indivíduos adultos. Os resultados encontrados mostram que as proporções de espécies analisadas limitadas espacial (90,3\%) e temporalmente (70,9\%) foram altas e a correlação entre LDe e LDT também foi alta (Spearman $=$ 0,8). Tanto para LDe como LDt, foram selecionados a massa média das sementes, a altura máxima e a frequência de distribuição de adultos. Em geral, as relações encontradas indicam que espécies com sementes maiores, com menor altura máxima e menor frequência de distribuição dos indivíduos adultos são mais limitadas espacial e temporalmente. Apesar desses fatores terem sido selecionados, houve uma grande variação nos efeitos para as espécies analisadas. O estudo reforça o fato do mecanismo de limitação de dispersão espacial ser frequentemente encontrado em comunidades arbóreas e apresenta uma abordagem temporal para o estudo da limitação de dispersão. A redução das interações competitivas interespecíficas, 
decorrente das altas limitações de dispersão observadas no estudo, se contrapõe às teorias amplamente aceitas (Janzen-Connell) que indicam os mecanismos de dispersão eficientes de sementes como uma forma de minimizar a competição intraespecífica. A importância relativa dos mecanismos de dispersão e de limitação de dispersão para a manutenção da diversidade em comunidades deveria ser estudada para avaliar em quais situações ou para quais conjuntos de espécies a coexistência é mediada pela ausência das interações intraespecíficas ou interespecíficas.

Palavras-chave: chuva de sementes, coexistência, estruturação de comunidades, fenologia, limitação de dispersão temporal. 


\section{Abstract}

The seed limitation has been empirically investigated as an equalizing mechanism of the competitive differences between species that coexists in plant communities. In addition to the spatial limitation, the temporal variations of seed dispersal can also be important to the species coexistence. The aim of the study was to investigate the relation between spatial seed limitation and temporal seed limitation and the species characteristics that influence both limitations. In a coastal plain forest, the seed rain was sampled over 36 months in 40 traps $\left(20 \mathrm{~m}^{2}\right), 100 \mathrm{~m}$ distant from each other and from the forest edges. The generalized mixed-effect models approach was used to test the relation between seed limitation and the average mass of the seeds, the dispersal syndrome, the trees local maximum height, and the adult trees distribution frequencies. The results show that the proportion of the analysed species spatial limited $(90,3 \%)$ e temporal limited $(70,9 \%)$ were high and the correlation between spatial seed limitation and temporal seed limitation were also high (Spearman $=0,8)$. To explain spatial seed limitation and temporal seed limitation were selected the average mass of seeds, the trees local maximum height and the adult trees distribution frequencies. Usually those relations indicate that species with lagger seeds, lowest maximum tree height and lowest adult trees distribution frequencies are more limited spatially and temporally. Although these factors have been selected, there was a great variation in the effects of the species analysed. The study supports the fact that the spatial seed limitation mechanism is frequently found in tree communities and shows a temporal approach to the seed limitation study. The reduction of interspecific competitive interactions, due to the high seed limitation 
observed in the study, is opposed to widely accepted theories (Janzen-Connell) that indicates that the efficient seed dispersal mechanism are a strategy to minimize the intraspecific competion. The relative importance of dispersal mechanisms and seed limitation on maintaning diversity in trees communities should be studied to evaluate which situations or which species sets the coexistence is mediated by the absence of intraspecific or interspecifir interactions.

Keywords: seed rain, coexistence, structuring communities, phenology, temporal seed limitation. 


\section{Introdução}

A riqueza de comunidades vegetais é definida por meio de mecanismos geradores e mantenedores da diversidade (MOUQUET \& LOREAU, 2002; HILLERISLAMBERS et al., 2012). Dentre os mecanismos geradores, a especiação e a dispersão em média e larga escala possibilitam o aumento da riqueza de espécies na comunidade (VELLEND, 2010). Os mecanismos mantenedores são aqueles que garantem a permanência das espécies na comunidade local em longo prazo (PALMER, 1994; WRIGHT, 2002; GIACOMINI, 2007). Um dos mecanismos mantenedores mais estudados é a diferenciação de nicho, em que cada espécie apresenta diferentes tolerâncias e exigências no uso de recursos, reduzindo a competição e possibilitando a coexistência entre elas (CHESSON, 2000; SILVERTOWN, 2004; FILE et al., 2011).

Entretanto, de acordo com a teoria neutra, espécies com nichos similares e que são consideradas funcionalmente equivalentes podem coexistir na comunidade (TILLMAN, 2004; HUBBELL, 2005). Considerando a similaridade entre as espécies, seria esperado que a comunidade fosse dominada por uma única espécie em um longo período de tempo devido a processos estocásticos demográficos. No entanto, as espécies conseguem se manter na comunidade quando há migração entre a comunidade local e a metacomunidade (HUBBELL, 2005). Por outro lado, existem mecanismos mantenedores que não dependem da migração em larga escala e permitem que espécies que competem pelos mesmos recursos, mas com diferentes habilidades competitivas, coexistam. Esses são chamados mecanismos equalizadores, que reduzem as diferenças competitivas entre as espécies e podem tornar a exclusão competitiva mais lenta, aumentando as chances de sobrevivência das piores 
competidoras (CHESSON, 2000). Um mecanismo equalizador que tem sido empiricamente investigado recentemente como possível mantenedor da diversidade em comunidades vegetais é a limitação de dispersão (HURTT \& PACALA, 1995; INMAN-NARAHARI et al., 2013).

Por serem organismos sésseis, as plantas se dispersam predominantemente por meio de frutos e sementes (PIJL, 1969). Entretanto, as sementes de uma determinada espécie geralmente não chegam a todos os locais propícios ao seu desenvolvimento (CLARK et al., 2007). Dessa forma, cada espécie apresenta uma limitação de dispersão que pode variar em relação às características da espécie (NATHAN \& MULLER-LANDAU, 2000). Se todas as espécies de uma comunidade tivessem alta capacidade de dispersão e apresentassem baixa limitação de dispersão, possivelmente existiria uma frequente interação competitiva entre as espécies vegetais, que resultaria na exclusão das espécies com menores habilidades competitivas (GAUSE, 1937). Por outro lado, considerando uma alta limitação de dispersão, as chances de que espécies com menor habilidade competitiva se estabeleçam aumentam devido às menores chances de encontro com melhores competidoras (HURTT \& PACALA, 1995; HUBBELL et al., 1999; BOLKER et al., 2003). Portanto, na escala da comunidade local, a limitação de dispersão permite que espécies com diferentes habilidades competitivas possam coexistir, sendo um importante mecanismo equalizador (CHESSON, 2000; INMAN-NARAHARI et al., 2013).

A limitação de dispersão espacial tem sido abordada em muitos estudos, entretanto, seria razoável supor que a limitação de dispersão temporal também possibilita a coexistência de espécies com diferentes habilidades competitivas. Estudos fenológicos descrevem a distribuição temporal das fenofases em comunidades vegetais, como floração, frutificação e a chuva de sementes 
(MORELLATO et al., 2000; MARQUES \& OLIVEIRA, 2004; MARTÍNEZ-GARZA et al., 2011; STAGGEMEIER \& MORELLATO, 2011; NADIA et al., 2012), mas, em geral, não relacionam diretamente esses padrões temporais à manutenção da diversidade vegetal em comunidades. Apenas MARQUES \& OLIVEIRA (2008) discutem a variação sazonal na chegada de sementes e no estabelecimento de plântulas como possíveis diferenciações de nicho em espécies vegetais em comunidades diversas. Muitos trabalhos relacionam a fenologia dos processos de frutificação e floração à diferenciação de nichos entre agentes dispersores e polinizadores, mas não em função da competição entre plântulas nas fases iniciais de estabelecimento. No entanto, o padrão temporal anual da chegada de sementes das espécies de uma comunidade pode ser importante para o sucesso nas próximas fases de vida (WANG \& SMITH, 2002), principalmente para espécies que germinam rapidamente. Se todas as espécies chegassem ao solo em todos os meses do ano, as interações competitivas no estágio de plântula recém-germinadas seriam mais frequentes, possivelmente resultando na exclusão de espécies com menor habilidade competitiva. Portanto, a chegada das sementes de uma espécie de maneira concentrada e em períodos distintos das outras espécies, possivelmente reduz a competição interespecífica nos estágios de vida mais críticos, como as plântulas. Similarmente à limitação de dispersão espacial, em que é vantajoso para as espécies apresentarem alta limitação espacial, poderia ser vantajoso concentrar a produção de sementes em poucos meses do ano. Dessa forma, seria vantajoso para as espécies apresentar alta limitação de dispersão espacial e temporal.

Algumas características morfológicas das sementes possivelmente estão relacionadas com a limitação de dispersão das espécies. O tamanho da semente tem sido considerado um bom indicador do potencial de dispersão de uma espécie 
(WESTOBY et al., 1996; ZHANG et al., 2004; LARIOS \& VENABLE, 2015). Devido ao peso ou comprimento da semente ela pode atingir diferentes distâncias de dispersão em relação à planta-mãe, sendo esperado que sementes menores atinjam maiores distâncias de dispersão (MULLER-LANDAU et al., 2008). Além disso, espécies que produzem sementes menores podem investir na produção de muitas sementes (PRIMACK, 1987) que seriam dispersas ao longo de vários meses (JACKSON, 1981), como é frequentemente observado entre as espécies classificadas como pioneiras (MUHANGUZI \& IPULET, 2012). Ao contrário, espécies que produzem sementes grandes e em menor quantidade seriam dispersas em poucos meses (JACKSON, 1981; HOWE \& SMALLWOOD, 1982; SUN et al., 1996), como as espécies consideradas tardias ou secundárias. Dessa forma, espécies com sementes menores tendem a ter dispersão menos limitada espacial e temporalmente do que plantas com sementes maiores.

Espécies que dependem de agentes dispersores distintos apresentam diferenças quanto à distância de dispersão (MULLER-LANDAU et al., 2008). Sementes dispersas por animais frugívoros como aves e mamíferos tendem a atingir distâncias de dispersão muito maiores do que sementes dispersas pelo vento ou aquelas sem adaptações morfológicas que atraiam algum tipo de dispersor (TAMME et al., 2014). Adicionalmente, as espécies com frutos que servem de alimento para os animais tendem a apresentar um período mais longo de produção de frutos (PESSOA et al., 2006; SELWYN \& PARTHASARATHY, 2007), possibilitando maior consumo e dispersão das sementes. Enquanto, as espécies que dependem do vento, concentram o amadurecimento dos frutos nas épocas mais secas do ano (JACKSON, 1981; GRITZ \& MACHADO, 2001; SELWYN \& PARTHASARATHY, 2007; CORTÉS-FLORES et al., 2013). Assim, a dispersão das sementes de espécies endozoocóricas tende a ser 
menos limitada espacial e temporalmente do que em espécies anemocóricas ou autocóricas.

Outras características que não são diretamente relacionadas com a morfologia da semente também podem ser importantes para a dispersão, como a altura máxima que os indivíduos adultos de uma determinada espécie podem atingir e a distribuição espacial desses adultos na comunidade. A altura máxima pode ser utilizada como um indicativo da capacidade reprodutiva e dispersora de uma determinada espécie. Espécies mais altas conseguem dispersar seus frutos e sementes a distâncias maiores (MULLER-LANDAU et al., 2008; THOMSON et al., 2011) e, além disso, a altura das árvores está relacionada com o estágio de desenvolvimento reprodutivo dos indivíduos indicando maior produção de frutos e sementes (ADLER \& KIELPINSKI, 2000; OTÁROLA et al., 2013; PIRES et al., 2013). Logo, quanto maior a altura dos indivíduos reprodutivos de uma espécie, menor a limitação de dispersão espacial.

Ademais, em alguns ambientes, a altura de uma árvore é essencial para que o organismo consiga captar mais energia luminosa para a realização de processos fisiológicos que proporcionam maior produção de frutos e sementes (KILKENNY \& GALLOWAY, 2008; DELERUE et al., 2013). Assim, como em ambientes abertos em que as espécies estão mais expostas à luminosidade e apresentam alta sincronia no período de floração e frutificação (KILKENNY \& GALLOWAY, 2008; VOGADO et al., 2016), as espécies que atingem maior altura devem conseguir produzir muitos frutos em poucos meses ao longo do ano. Por outro lado, há evidências de que maior luminosidade pode prolongar o período reprodutivo se comparado aos locais menos expostos à luminosidade (GALLOWAY \& BURGESS, 2012). Portanto, dependendo do ambiente, a altura dos indivíduos reprodutivos de uma espécie pode resultar em maior ou menor limitação de dispersão temporal. 
Adicionalmente, a distribuição espacial dos indivíduos adultos reprodutivos pode ser um parâmetro essencial para prever a limitação de dispersão das espécies de uma comunidade. Considerando que a maior proporção de frutos e sementes produzidos pelos indivíduos tende a se concentrar abaixo ou próximo da planta-mãe (FLORES-MORENO et al., 2013; LARIOS \& VENABLE, 2015), a localização e a distribuição espacial dos adultos reprodutivos devem ser importantes para prever em quantos e quais locais as sementes de uma determinada espécie têm maiores chances de chegar. Assim, espécies que estão mais distribuídas espacialmente tendem a apresentar menor limitação de dispersão espacial. Da mesma maneira, esse padrão de distribuição espacial das árvores pode fazer com que os indivíduos da mesma espécie fiquem expostos a diferentes condições microclimáticas, porque encontram-se em clareiras, bordas de mata ou locais mais sombreados. Essas diferenças podem reduzir a sincronia na época de produção dos frutos entre os indivíduos da população e fazer com que o período de chegada das sementes aumente (REZNIK et al., 2012; SOUZA et al., 2013). Logo, a distribuição mais esparsa dos indivíduos adultos também deve proporcionar menor limitação de dispersão temporal.

Considerando a importância do mecanismo de limitação de dispersão como estruturador de comunidades e mantenedor da coexistência de espécies (HURTT \& PACALA, 1995; HUBBELL et al., 1999; DALLING et al., 2002; BOLKER et al., 2003; INMAN-NARAHARI et al., 2013) e, consequentemente, o interesse em prever as características que descrevem a limitação de dispersão, os objetivos deste trabalho foram: (i) verificar se existe relação entre a limitação de dispersão espacial e a limitação de dispersão temporal para espécies arbóreas de uma comunidade da Floresta de planície costeira e; (ii) investigar se as mesmas características que descrevem a limitação de dispersão espacial também descrevem a limitação de 
dispersão temporal. Esperamos que (i) as espécies sejam, em geral, bastante limitadas espacial e temporalmente e que exista uma relação positiva entre os dois tipos de limitação; (ii) as mesmas características descrevam a limitação de dispersão espacial e temporal. Dentre as características, esperamos que espécies com sementes maiores, dispersas por agentes abióticos, com menor altura máxima e distribuição espacialmente agregada dos indivíduos adultos em geral apresentem maior limitação de dispersão espacial e temporal. 


\section{Material e Métodos}

\section{1. Área de estudo}

O trabalho foi realizado em um fragmento de 72 hectares, localizado a $6 \mathrm{~m}$ acima do nível do mar, na planície costeira do município de Caraguatatuba, Estado de São Paulo, Brasil (233'22,8'’S e 45²6'59,2'’O). Segundo a classificação climática de KÖPPEN (1948), a região apresenta clima Af tropical úmido sem estação seca definida. A temperatura média anual é de $25^{\circ} \mathrm{C}$ e a precipitação anual média de 1750 mm, sendo julho o mês mais seco, com média de 68 mm, e janeiro o mês mais úmido, com média de $270 \mathrm{~mm}$.

A topografia regional é plana a ondulada, sendo que as áreas mais baixas são suscetíveis ao alagamento. Devido aos frequentes deslizamentos de terra que ocorrem na Serra do Mar do Estado de São Paulo, o solo da região apresenta uma camada argilosa superficial sobre a planície arenosa (FERREIRA, 2013). O solo na área de estudo é arenoso a argilo-arenoso, ácido $(\mathrm{pH}<4,0)$, infértil e está constantemente sujeito a alagamentos em grande parte do ano em função da variação no nível do lençol freático (PANSONATO et al., dados não publicados; Figura 1A). Dessa forma, a vegetação do fragmento estudado apresenta algumas particularidades se comparada às outras regiões da planície costeira. De acordo com PANSONATO e colaboradores (dados não publicados), a área de estudo deve ser classificada como Floresta Alta de Restinga Úmida, seguindo a nomenclatura proposta por SOUZA e colaboradores (2009). Essa fisionomia é bastante diversificada devido à oscilação do lençol freático ao longo do ano. Nas áreas que inundam por um curto período no ano, o dossel varia de fechado a aberto, com indivíduos arbóreos com $16 \mathrm{~m}$ de altura em média e algumas espécies emergentes até 27 m (MARTINS et al., 2008, Figura 1B). 

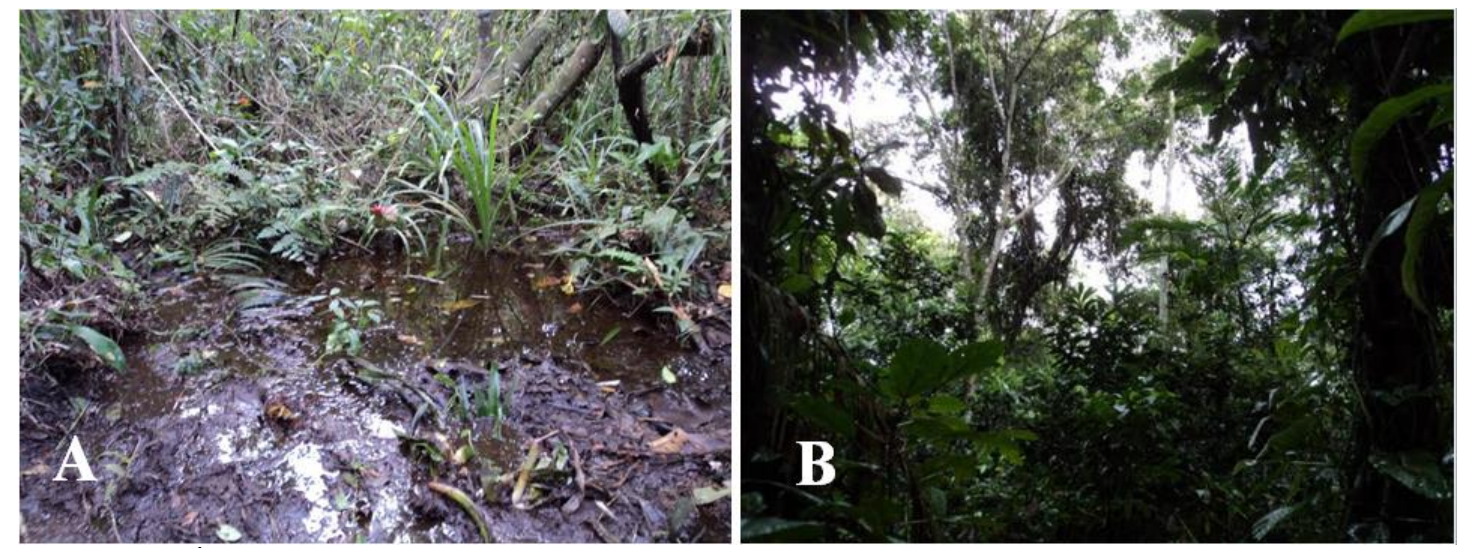

Figura 1. Área de estudo. Em A, solo alagado devido ao nível do lençol freático e, em B, estrutura do dossel arbóreo aberto a fechado, com alguns indivíduos emergentes. A área foi classificada como Floresta Alta de Restinga Úmida (PANSONATO et al., dados não publicados).

\section{Levantamento das espécies arbóreas}

$\mathrm{Na}$ área de estudo, foram instaladas 40 parcelas de 20 x 20m não contíguas, distantes $80 \mathrm{~m}$ entre si e pelo menos $30 \mathrm{~m}$ distantes da borda do fragmento, totalizando uma área de 1,6 hectares amostrada (Figura 2). Em cada parcela foi realizado o levantamento dos indivíduos arbóreos adultos a partir de 4,8cm de diâmetro a altura do peito (DAP) (PANSONATO et al., dados não publicados). Esse critério foi utilizado baseando-se em outros levantamentos fitossociológicos realizados em ambientes florestados (MORO \& MARTINS, 2011). Quando possível, a identificação dos exemplares arbóreos-arbustivos foi realizada em campo, caso contrário, alguns ramos eram coletados para posterior identificação em herbários ou com o auxilio de especialistas. Alguns dados obtidos no levantamento das espécies arbóreas foram utilizados nesse estudo. A frequência de ocorrência dos indivíduos adultos foi aplicada como variável operacional da distribuição espacial das espécies na comunidade. Enquanto a altura estimada dos indivíduos arbóreos foi utilizada para a obtenção da altura máxima local para cada uma das espécies (ANEXO 1). 


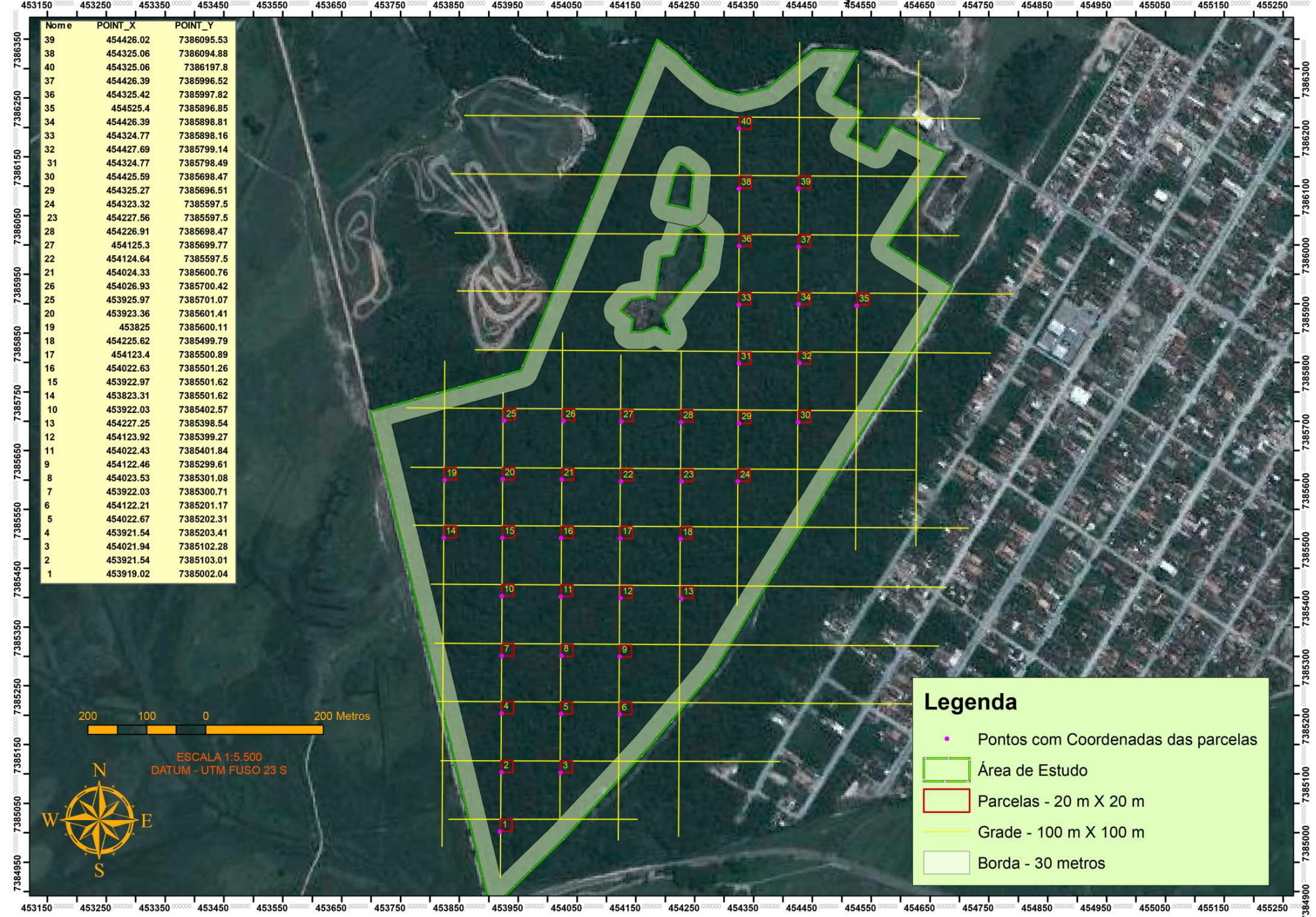

Figura 2. Mapa da área de estudo, um fragmento de 72 hectares localizado na planície costeira do município de Caraguatatuba, Estado de São

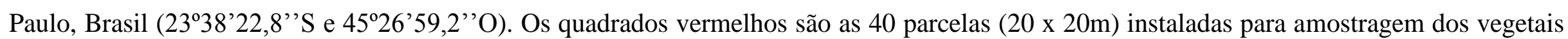
arbóreos. 


\section{Chuva de sementes}

No centro de cada parcela da área de estudo, foi instalado um coletor de sementes quadrado com área de $0,5 \mathrm{~m}^{2}$, suspenso a $50 \mathrm{~cm}$ do solo, construído com estrutura em PVC e tela de nylon com malha de $1 \mathrm{~mm}^{2}$ (Figura 3). Mensalmente, ao longo de 36 meses, todo o material depositado nos coletores foi retirado e levado para o laboratório para secagem e triagem. A coleta começou em outubro de 2012 e terminou em setembro de 2015. Todos os frutos e sementes com tamanho superior a 1 mm foram separados por morfoespécie e depois identificados por meio da coleção de sementes do Laboratório de Ecologia de Florestas Tropicais (Labtrop - IB-USP), do auxílio de especialistas do Herbário Dom Bento Pickel (SPSF) e de consulta ao banco de dados de sementes do Smithsonian Tropical Research Institute disponível online e à literatura (Lorenzi, 2009; Lorenzi, 2010). Após a identificação, foi obtido o número total de sementes para cada espécie arbórea.

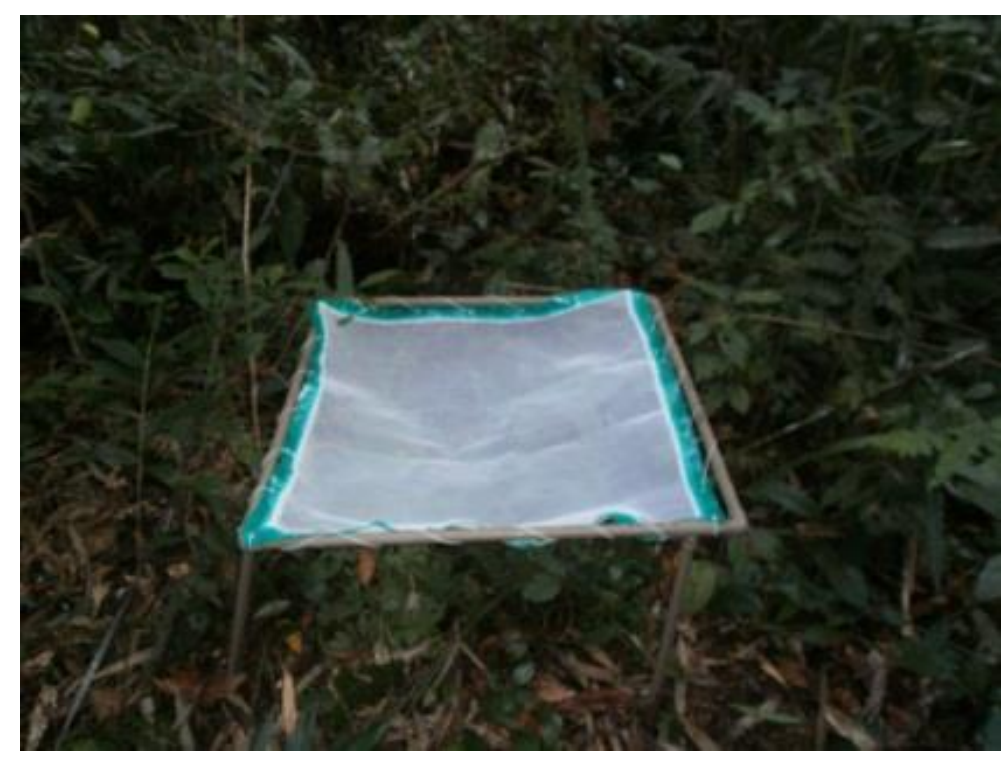

Figura 3. Coletor de sementes utilizado para a coleta de chuva de sementes em um fragmento de planície costeira no município de Caraguatatuba, Estado de São Paulo,

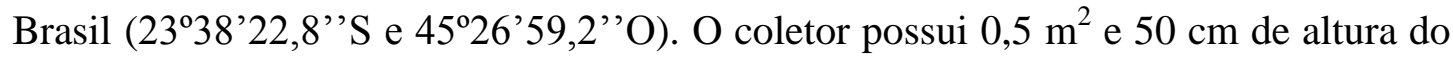
solo. 


\section{Análise de dados}

\subsection{Variações sazonais na chuva de sementes}

Para verificar se a chegada de sementes se mantém ao longo de todos os meses do ano e para analisar se existe sincronia temporal na abundância de sementes e na riqueza de espécies amostradas na chuva de sementes ao longo dos 36 meses de estudo, foi calculado o vetor médio (r) de distribuição dos dados. Um maior comprimento do vetor indica menos uniformidade na distribuição dos valores e maior sincronia temporal. Além disso, foi realizado um Teste de Rayleigh (Z) que, por meio de estatística circular, testa a concentração dos dados em torno do vetor médio (TALORA \& MORELLATO, 2000). Portanto, quando os dados são uniformes (assincronia) a concentração em torno de $\mathrm{r}$ é baixa, logo o resultado do teste não será significativo ( $p>0,05)$. No entanto, quando os dados não são uniformes (sincronia) a concentração dos dados em torno de $\mathrm{r}$ é alta e o resultado do teste é significativo ( $\mathrm{p}$ $<0,05)$. O teste foi realizado no ambiente R 3.1.3 (R Development Core Team, 2016) com o pacote circular (AGOSTINELLI \& LUND, 2013).

\subsection{Limitação de dispersão espacial e temporal (LDe e LDt)}

A taxa de limitação de dispersão espacial (LDe) das sementes foi calculada anualmente para cada espécie da comunidade por meio da equação 1, abaixo (Nathan \& Muller-Landau, 2000):

$$
\mathrm{LDe}=1-(\mathrm{NC} / \mathrm{n})
$$

em que,

$\mathrm{NC}=$ número de coletores em que a espécie foi encontrada;

$\mathrm{n}=$ número total de coletores 
esse índice varia de 0 a 1 , sendo 0 sem limitação de dispersão espacial alguma e 1 completa limitação de dispersão espacial.

Essa taxa foi obtida a partir dos dados da chuva de sementes amostrada em cada ano do estudo para cada uma das espécies arbóreas da comunidade. A abundância de sementes nos coletores não foi considerada para o cálculo da LDe, foram apenas utilizados os dados de presença e ausência das sementes em cada coletor, conforme explicitado na equação 1 .

A taxa de limitação de dispersão temporal (LDt) das sementes foi calculada para cada espécie da comunidade por meio da equação 2, abaixo:

$$
\mathrm{LDt}=1-(\mathrm{NM} / \mathrm{a})
$$

em que,

$$
\begin{aligned}
& \mathrm{NM}=\text { número de meses (em um ano) que a espécie foi encontrada em } \\
& \text { pelo menos um coletor; } \\
& \mathrm{a}=\text { número total de meses no ano }=12 \text { meses }
\end{aligned}
$$

esse índice varia de 0 a 1 , sendo 0 sem limitação de dispersão temporal alguma e 1 completa limitação de dispersão temporal.

Essas taxas foram obtidas para cada uma das espécies arbóreas da comunidade amostrada na chuva de sementes. Cada espécie apresenta três valores de LDe e três valores de LDt, sendo um para cada ano do estudo.

\subsection{Relação entre a limitação de dispersão espacial e temporal}

Para verificar se existe relação entre LDe e LDt das espécies arbóreas da comunidade, considerando os três anos de amostragem, foi feito um teste de correlação de Spearman. A correlação de Spearman é um teste não-paramétrico que 
mede a variância compartilhada entre duas variáveis (LDe e LDt) que não seguem uma distribuição normal. Nesse estudo iremos considerar alta apenas correlações acima de 0,70. O teste foi realizado no ambiente R 3.1.3 (R DEVELOPMENT CORE TEAM, 2016).

\subsection{Características que influenciam a limitação de dispersão espacial e temporal}

Para verificar quais características estão relacionadas à limitação de dispersão espacial e temporal das espécies arbóreas da comunidade foi utilizada a abordagem de modelos lineares generalizados mistos. Essa abordagem permite a construção de modelos lineares com variáveis que não seguem necessariamente uma distribuição normal. Adicionalmente, a abordagem de modelos mistos é vantajosa porque, por meio da inclusão dos fatores aleatórios, é possível lidar com dados hierárquicos e com a dependência entre os dados (GRUEBER et al., 2011). No caso deste estudo, a identidade das espécies arbóreas da comunidade é um exemplo de dado hierárquico e dependente, sendo que o táxon agrupa indivíduos semelhantes entre si. Além disso, o ano de amostragem representa um grau de dependência entre as amostras. Dessa forma, nos modelos testados foram considerados como fatores aleatórios a espécie e o ano de amostragem e foi verificado o efeito desses fatores sobre a variação em LDe e LDt. A abordagem de modelos mistos permite testar os efeitos de variáveis de interesse, chamadas de fatores fixos, descontando erros associados aos efeitos de variáveis aleatórias sobre uma variável dependente (neste estudo, LDe e LDt) (ZUUR et al., 2009). Os fatores fixos testados e as respectivas previsões estão descritas abaixo: 


\section{Massa média das sementes (M)}

Para obter a massa média das sementes de uma espécie, foram sorteadas 10 sementes que caíram nos coletores em qualquer uma das parcelas, meses e anos. Para as espécies mais abundantes na chuva de sementes, foram sorteadas 50 sementes. Espera-se que espécies com sementes maiores apresentem maior LDE e LDT. Portanto, o aumento na massa média das sementes deve ter um efeito positivo sobre a limitação de dispersão.

\section{Altura máxima $(H)$}

Para testar se a altura máxima local influencia LDE e LDT foram utilizados os dados do levantamento arbóreo (PANSONATO et al., dados não publicados). Esperase que espécies com menor altura máxima apresentem maior LDE e LDT. Portanto, o aumento na altura máxima deve ter um efeito negativo sobre a limitação de dispersão.

\section{Frequência das espécies arbóreas adultas na comunidade $(F)$}

A frequência das espécies arbóreas (ANEXO 1) na comunidade foi obtida como uma proporção do número de parcelas em que uma determinada espécie ocorre em relação ao número total de parcelas amostradas $(\mathrm{N}=40)$. Espera-se que espécies arbóreas adultas menos frequentes apresentem maior LDE e LDT. Portanto, o aumento na frequência deve ter um efeito negativo sobre a limitação de dispersão.

Inicialmente, seria esperado que a chegada das sementes nos coletores pudesse ser prevista majoritariamente por meio da frequência de distribuição dos indivíduos adultos na comunidade. Pelo método de amostragem utilizado, a chegada de sementes deveria estar fortemente relacionada às espécies mais frequentes, uma vez que os coletores teriam maior probabilidade de serem colocados próximos aos indivíduos 
dessas espécies. Dessa forma, a frequência foi considerada em todos os modelos estatísticos testados para a variável resposta LDe, visando compensar essa possível diferença de probabilidades.

Síndrome de dispersão $(S D)$

A síndrome de dispersão diz respeito ao agente responsável pela dispersão de uma determinada espécie arbórea. Neste trabalho, as espécies foram classificadas de acordo com os atributos das sementes que permitissem identificar qual o principal agente dispersor da espécie (PIJL, 1969). As sementes endozoocóricas são aquelas revestidas de frutos ou arilos carnosos e nutritivos, atrativos para a fauna. Muitas vezes essas estruturas já haviam sido removidas quando caíam nos coletores. Nesses casos, após a identificação, a síndrome de dispersão foi definida a partir de dados disponíveis na literatura (Lorenzi, 2009; Lorenzi, 2010). As sementes classificadas como anemocóricas são as que possuem estruturas aerodinâmicas como alas e plumas que permitem o transporte aéreo da semente. Por fim, as sementes classificadas como autocóricas são sementes sem características morfológicas que facilitem a dispersão (HOWE \& SMALLWOOD, 1982). Espera-se que espécies endozoocóricas apresentem menor limitação de dispersão do que espécies anemocóricas e autocóricas, portanto, a síndrome de endozoocoria deve ter um efeito negativo e mais intenso sobre LDE e LDT.

A partir dos fatores fixos descritos acima, foram construídos todos os modelos possíveis a partir da combinação desses fatores além do modelo nulo somente com os fatores aleatórios. Além destes fatores fixos isolados também foram testadas 
interações biologicamente plausíveis entre os seguintes fatores: M e SD, M e H, H e SD, F e M, F e H, F e SD.

\section{Interação entre $M$ e SD}

Sementes mais leves são mais facilmente dispersas. No entanto, costumam ser dispersas pelo vento que não é o agente dispersor mais eficiente. Sementes mais pesadas são mais limitadas quanto à dispersão espacial. No entanto, costumam ser dispersas por animais que são agentes dispersores mais eficientes. Dessa forma, espera-se que o efeito da massa sobre LDe seja positivo, entretanto seja ainda maior para as espécies dispersas por agentes abióticos.

No aspecto temporal, também espera-se que o efeito da massa sobre LDt seja positivo e mais significativo para as espécies dispersas por agentes abióticos. Considerando que sementes grandes são produzidas em menor quantidade e o custo de produzi-las é alto, possivelmente essas espécies devem produzir sementes em épocas mais propícias e durante um curto período de tempo quando comparado às espécies que produzem sementes menores. Além disso, as espécies com sementes grandes que são dispersas pelo vento também devem apresentar maior limitação temporal, pois concentram a produção de sementes nas épocas mais secas do ano.

\section{Interação entre $M$ e $H$}

Considerando que a massa da semente apresenta efeito positivo sobre LDe e LDt e a altura máxima apresenta efeito negativo, espera-se que a interação das duas variáveis gere um efeito positivo, porém menor, sobre a limitação de dispersão. Assim, espera-se que as espécies com sementes e indivíduos arbóreos maiores tenham 
LDe e LDt menores do que as espécies com sementes grandes e indivíduos arbóreos menores.

\section{Interação entre $H$ e $S D$}

O efeito da altura pode ser oposto para espécies dispersas por vetores diferentes. Por exemplo, espera-se que em espécies anemocóricas a altura tenha um efeito negativo sobre a limitação de dispersão, possibilitando que as sementes atinjam maiores distâncias. No entanto, para espécies endozoocóricas espera-se que não exista diferença no efeito da altura sobre LDe. Espera-se também que para as espécies autocóricas, a altura deva apresentar um efeito negativo sobre a limitação de dispersão, porém menor do que em espécies anemocóricas.

Por outro lado, no aspecto temporal, considerando que maior exposição à luminosidade aumenta a produção de frutos, espera-se que o efeito da altura sobre a limitação de dispersão temporal seja negativo para as espécies dispersas por animais que tendem a prolongar o período de produção de frutos. Entretanto, para as espécies anemocóricas mais altas deve ser vantajoso secar rapidamente para evitar a competição com outras espécies. Assim, para espécies anemocóricas, espera-se um efeito positivo da altura sobre LDt.

\section{Interação entre $F$ e $M$}

Considerando que a frequência das espécies arbóreas apresenta efeito negativo sobre LDe e LDt e a massa da semente apresenta efeito positivo, espera-se que espécies bastante frequentes e com sementes pequenas apresentem menor LDe e LDt do que espécies bastante frequentes mas com sementes grandes. 


\section{Interação entre $F$ e $H$}

Considerando que a altura máxima e a frequência dos indivíduos arbóreos apresentam efeito negativo sobre LDe e LDt, espera-se que a interação entre as duas variáveis vá intensificar o efeito sobre as limitações. Dessa maneira, espera-se que as espécies arbóreas mais frequentes e mais altas apresentem menor limitação de dispersão em relação às espécies mais frequentes porém menos altas.

\section{Interação entre $F$ e SD}

Em geral, espera-se que as espécies mais frequentes apresentem menor LDe. Entretanto, considerando que as espécies dispersas por animais tendem a ser melhores dispersas, espera-se que o efeito negativo da frequência seja ainda maior para as espécies dispersas por animais. Da mesma maneira, espera-se que o efeito negativo da frequência sobre LDt seja maior ainda para as espécies dispersas por animais, pois essas espécies costumam produzir frutos por um período maior e a maior frequência de ocorrência dessas espécies pode indicar que diferentes indivíduos estejam produzindo frutos em períodos distintos.

Todos os fatores fixos quantitativos ( $\mathrm{M}, \mathrm{H} \mathrm{e} \mathrm{F}$ ) foram escalonados para o escore $\mathrm{Z}$ para que pudessem ser comparados. Essa forma de escalonamento transforma os valores da variável em números adimensionais que estão organizados em torno da média da variável e permite que variáveis com dimensões muito discrepantes sejam comparadas. Para transformar uma variável no escore Z, para cada um dos valores da variável foi feita a diferença em relação à média da variável e essa diferença foi dividida pelo desvio padrão da amostra. 
A seleção dos modelos que melhor descrevem LDe e LDt foi realizada segundo o critério de informação de Akaike corrigido para amostras pequenas (AICc ), considerando que modelos com $\triangle \mathrm{AICc}<2$ são igualmente plausíveis (BURNHAM \& ANDERSON, 2002). Os modelos mistos foram construídos no pacote lme4 (BATES et al., 2011), o cálculo do AICc foi efetuado no pacote bbmle (BOLKER, 2013) e a montagem dos modelos candidatos foi feita no pacote MuMIn (BARTON, 2016) no ambiente R 3.1.3 (R DEVELOPMENT CORE TEAM, 2016).

As sementes de espécies que chegaram à chuva de sementes, mas que não foram amostradas no levantamento arbóreo não foram incluídas nas análises. Além disso, foram incluídas somente espécies cuja quantidade mínima de sementes amostradas ao longo dos 36 meses do estudo era superior a $10 \%$ do número de coletores. Portanto, foram consideradas espécies com pelo menos 5 sementes amostradas e, consequentemente, teriam chances de estarem presentes em pelo menos $10 \%$ dos coletores. Por fim, as sementes que foram identificadas até o nível de gênero e que poderiam causar algum tipo de incerteza também não foram incluídas nas análises. Considerando todos os critérios de inclusão apresentados acima, 51 morfotipos coletados na chuva de sementes não foram considerados nas análises de correlação e de seleção de modelos. 


\section{Resultados}

\section{Descrição geral da chuva de sementes}

Ao longo dos 36 meses de estudo foram coletadas 18597 sementes $(25,83$ sementes $/ \mathrm{m}^{2}$.mês) de 81 espécies arbóreas distribuídas em 32 famílias. A família com maior riqueza de espécies amostrada foi Myrtaceae (22 espécies) e a família mais abundante na chuva de sementes foi Urticaceae $(68,4 \%$ das sementes - representada pelas espécies Coussapoa microcarpa e Cecropia spp.). Dentre as 81 espécies de sementes coletadas, 13 não foram amostradas no levantamento arbóreo (ANEXO 1), como Cupania sp./Matayba sp. (27 sementes) e Dictyoloma vandellianum (8 sementes) (ANEXO 2). Considerando toda a amostragem, foram coletadas 17562 sementes endozoocóricas $(94,4 \%)$ pertencentes a 64 espécies, 335 sementes anemocóricas $(1,8 \%)$ distribuídas em 13 espécies e 700 sementes autocóricas $(3,8 \%)$ de 4 espécies. Além dessas espécies, também foram coletadas muitas sementes de Ficus spp. que não foram contabilizadas, pois o tamanho estava no limite do critério de inclusão $\left(\sim 1 \mathrm{~mm}^{2}\right)$ ou eram encontradas em aglomerados difíceis de distinguir entre fezes ou frutos deteriorados (ANEXO 2).

Considerando todas as espécies e morfotipos arbóreos identificados na chuva de sementes, ao longo dos três anos de amostragem, apenas duas espécies estiveram presentes em mais de $75 \%$ dos coletores (Coussapoa microcarpa e Myrsine spp.), enquanto 55 espécies apareceram em no máximo 10\% dos coletores (Figura 4). Quanto às espécies amostradas no levantamento arbóreo, 52\% das espécies (73 espécies) estavam ausentes na chuva de sementes. Além da variação espacial, as espécies variaram quanto ao número de meses em que chegaram sementes. Apenas 
duas espécies estavam presentes em mais de $75 \%$ dos meses ao longo do ano (Coussapoa microcarpa e Schefflera angustissima), enquanto $78 \%$ das espécies (64 espécies) estavam presentes em no máximo 25\% dos meses (ANEXO 2 e 3).

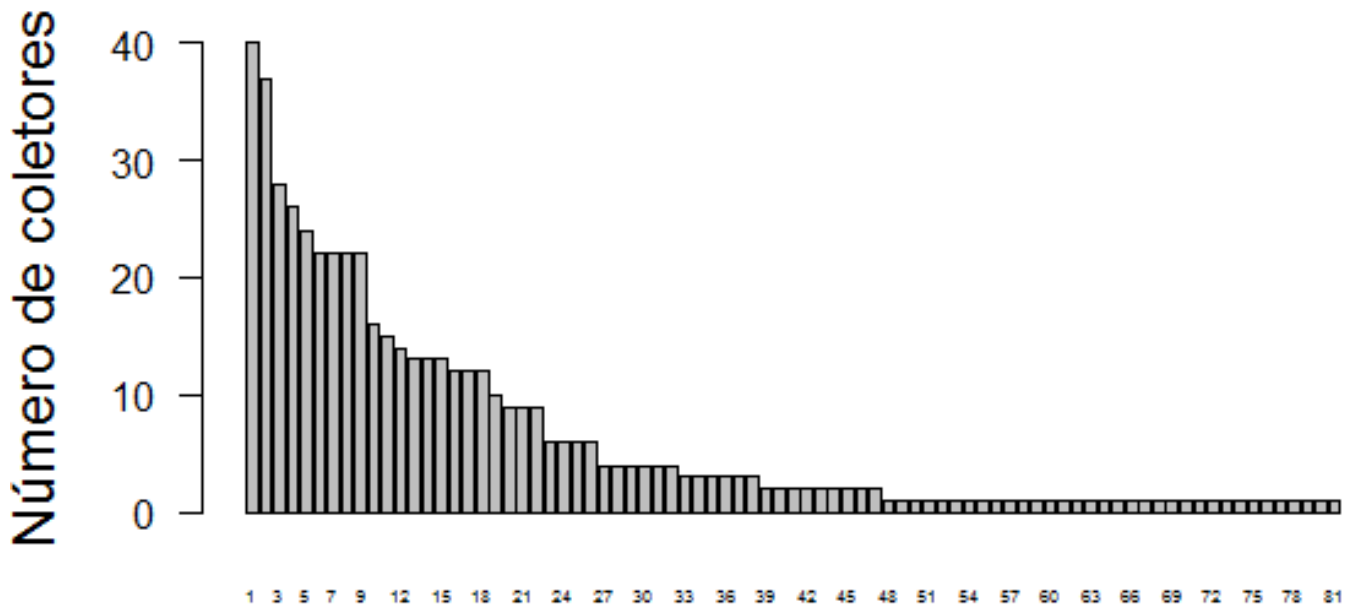
Espécies arbóreas na chuva de sementes

Figura 4. Número de coletores em que as sementes das espécies amostradas na chuva de sementes ( $\mathrm{N}=81$ espécies) foram encontradas ao longo de três anos de amostragem. Os nomes das espécies podem ser vistos no ANEXO 2.

Considerando a variação temporal da chuva de sementes amostrada, em média foram coletadas sementes de 13,11 $\pm 2,17$ ( \pm desvio padrão) espécies por mês, sendo que o mês com a menor riqueza média foi o mês de setembro $(10,33 \pm 5,86$ espécies $)$ e o mês com maior riqueza média foi o mês de julho $(16,67 \pm 0,58$ espécies $)$. Entretanto, essa diferença não é significativa e, portanto, não é possível perceber um período de maior riqueza de espécies chegando aos coletores (Figura 5A; $\mathrm{p}=0,709 ; \mathrm{r}$ $=0,048)$. Por outro lado, em relação à abundância de sementes que chegam ao longo dos meses nos coletores é possível perceber diferenças em relação aos meses do ano 
(Figura 5B; $\mathrm{p}<0,001 ; \mathrm{r}=0,456$ ). Em média foram coletadas 456,03 $\pm 339,84$ sementes por mês, sendo que o mês com a menor abundância média foi o mês de agosto $(52,33 \pm 34,59$ sementes $)$ e o mês com maior abundância média foi o mês de janeiro (1135 $\pm 583,96$ sementes). Portanto, existe um pico de produção de sementes no verão apesar da riqueza de espécies se manter constante ao longo do ano, sendo Coussapoa microcarpa a principal espécie responsável por esse pico na abundância de sementes.

A

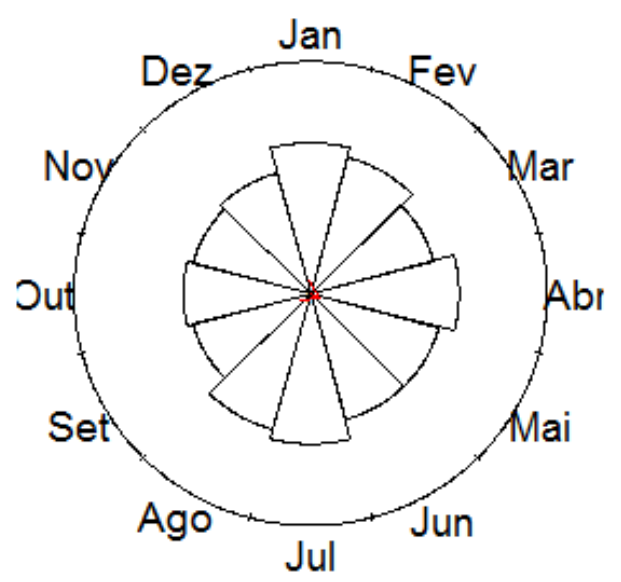

B

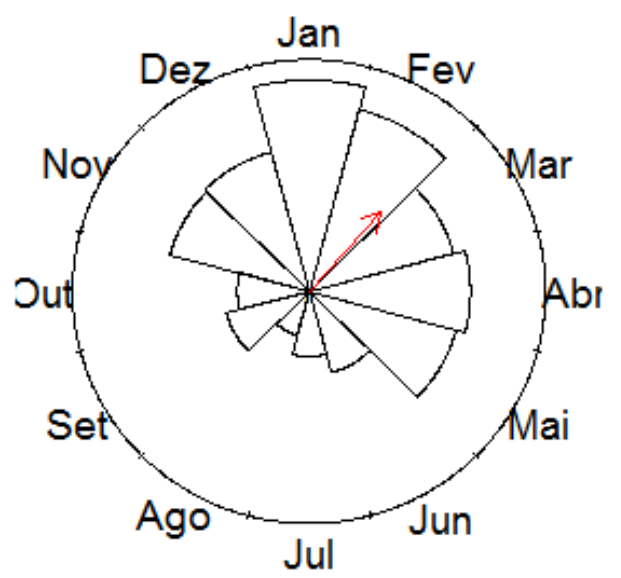

Figura 5. Padrão temporal da distribuição da chuva de sementes em um fragmento da planície costeira no município de Caraguatatuba, Estado de São Paulo, Brasil ( $23^{\circ} 38^{\prime} 22,8^{\prime}$ 'S e $45^{\circ} 26^{\prime} 59,2$ ' 'O). A = distribuição da riqueza média de espécies para cada mês do ano ao longo dos três anos de estudo; $\mathrm{B}=$ distribuição da quantidade média de sementes para cada mês do ano ao longo dos três anos de estudo. O tamanho das barras radiais representa a raiz quadrada da frequência relativa da riqueza de espécies (A) e da abundância de sementes (B) na chuva de sementes. O vetor (seta vermelha) indica o período do ano com maior riqueza de espécies (A) ou abundância de sementes (B) e o comprimento desse vetor é um indício de sincronia temporal. 


\section{Relação entre limitação de dispersão espacial e temporal}

A limitação de dispersão espacial das 31 espécies analisadas variou de 0,025 a 1,0 e a mediana foi de 0,95 , enquanto a limitação de dispersão temporal variou de 0 a 1,0 e a mediana foi de 0,833 , mostrando que as espécies em geral foram muito limitadas (ANEXO 2). Entre os anos amostrados, as limitações de dispersão espacial e temporal das espécies não variaram muito, com exceção de Nectandra oppositifolia que apresentou uma amplitude maior na limitação de dispersão espacial $(0,525-0,925)$ e as espécies Anaxagorea dolichocarpa e Amaioua intermedia, que apresentaram maior variação na limitação de dispersão temporal $(0,583$ a 0,917 e $\quad 0,583$ a $\quad 1,0$ respectivamente) entre os três anos de estudo (ANEXO 2).

A correlação entre a limitação de dispersão espacial e a limitação de dispersão temporal foi $0,888(\mathrm{~N}=93$ pontos referente a 31 espécies nos três anos; Figura 6). Como esperado, todas as espécies com alta LDt $(0,8$ a 1,0) apresentaram alta LDe $(0,8$ a 1,0). No entanto, as espécies com alta LDe $(0,8$ a 1,0) apresentaram grande variação em relação à LDt, apresentando valores entre 0,2 e 1,0. Além disso, espécies com baixa LDt $(0,0$ a 0,3) também apresentaram uma grande variação em relação à $\mathrm{LDe}$, com valores entre 0,0 e 0,8 .

\section{Características que influenciam a limitação de dispersão espacial e} temporal

Dentre as 31 espécies utilizadas na análise de seleção de modelos mistos, 27 delas eram endozoocóricas, duas anemocóricas e as outras duas autocóricas. A massa das sementes dessas mesmas espécies variou de 0,0014 g a 1,3 g, com média 0,235 g e mediana 0,074 g. A frequência de indivíduos adultos na comunidade das espécies utilizadas na análise de seleção de modelos variou de 0,025 a 0,9, com média 0,332 e 
mediana 0,3, sendo as espécies mais frequentes Diospyros brasiliensis, Alchornea triplinervia e Sloanea guianensis (ANEXO 2). A altura máxima local dos indivíduos arbóreos variou de $3,5 \mathrm{~m}$ a $23 \mathrm{~m}$, com média 14,08 m e mediana $15 \mathrm{~m}$ (Figura 7; ANEXO 2).

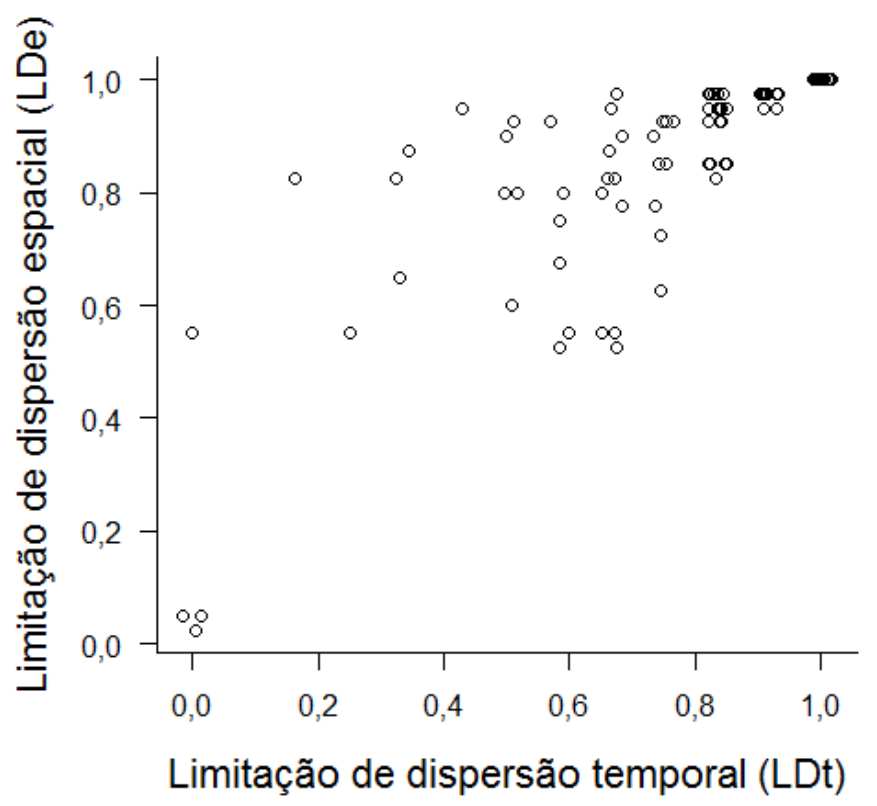

Figura 6. Correlação entre a limitação de dispersão espacial e a limitação de dispersão temporal das espécies arbóreas da comunidade que foram amostradas na chuva de sementes em um fragmento da planície costeira do município de Caraguatatuba, Estado de São Paulo, Brasil (N=93 pontos referentes a 31 espécies em três anos). Devido à sobreposição de algumas observações no gráfico, para cada um dos valores estatísticos (pontos no gráfico) foi adicionado um pequeno valor aleatório aos valores reais de LDt para que essas observações sobrepostas pudessem ser visualizadas no gráfico. 


\section{Limitação de dispersão espacial (LDe)}

Os fatores que influenciaram a limitação de dispersão espacial foram a frequência de indivíduos arbóreos adultos $(\mathrm{F})$, a altura máxima local desses indivíduos arbóreos $(\mathrm{H})$ e a massa média das sementes das espécies arbóreas (M), ordenados pelos fatores que apareceram primeiro nos modelos mais plausíveis (Tabela 1). De acordo com os coeficientes estimados pelos modelos plausíveis $(\Delta \mathrm{AICc}<2)$, puderam ser observadas algumas tendências em relação ao efeito desses fatores fixos sobre LDe. A limitação de dispersão espacial foi influenciada positivamente por $\mathrm{M}$, porém negativamente por $\mathrm{F}$ e $\mathrm{H}$. Considerando os intervalos de confiança dos coeficientes estimados, podemos observar que a variação foi grande e incluiu o zero, mesmo descontando-se os efeitos aleatórios. A síndrome de dispersão não foi selecionada por nenhum dos modelos considerados plausíveis.

\section{Limitação de dispersão temporal (LDt)}

Os fatores que influenciaram a limitação de dispersão temporal foram massa média das sementes das espécies arbóreas (M), altura máxima local dos indivíduos adultos $(\mathrm{H})$ e frequência desses indivíduos arbóreos adultos (F) (Tabela 2). Os fatores M, H e F apareceram nesta ordem entre os melhores modelos selecionados, porém esses modelos selecionados não diferiram do modelo nulo. De acordo com os coeficientes estimados pelos modelos plausíveis $(\Delta \mathrm{AICc}<2)$, puderam ser observadas algumas tendências em relação ao efeito desses fatores fixos sobre LDt. Entretanto, devido à alta variação nos valores do coeficiente, incluindo o zero, podemos observar que a relação entre os fatores fixos e a variável resposta é fraca (Tabela 2). Ainda assim, a relação entre limitação de dispersão temporal e M foi positiva, enquanto a relação entre LDt e H e LDt e F foram negativas. A variável 
síndrome de dispersão não foi selecionada em nenhum dos modelos considerados plausíveis.

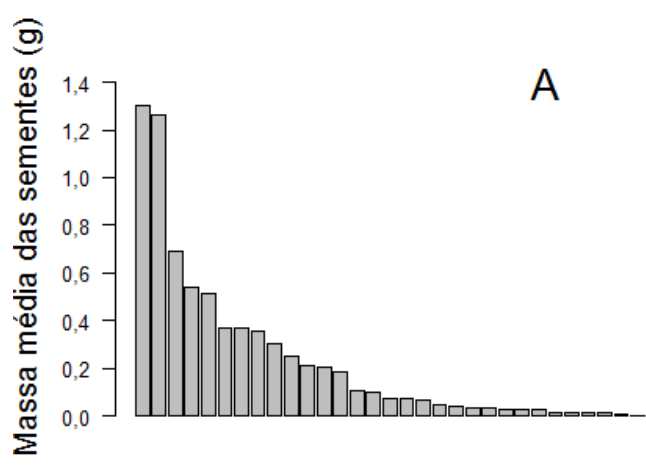

Espécies arbóreas analisadas (31)
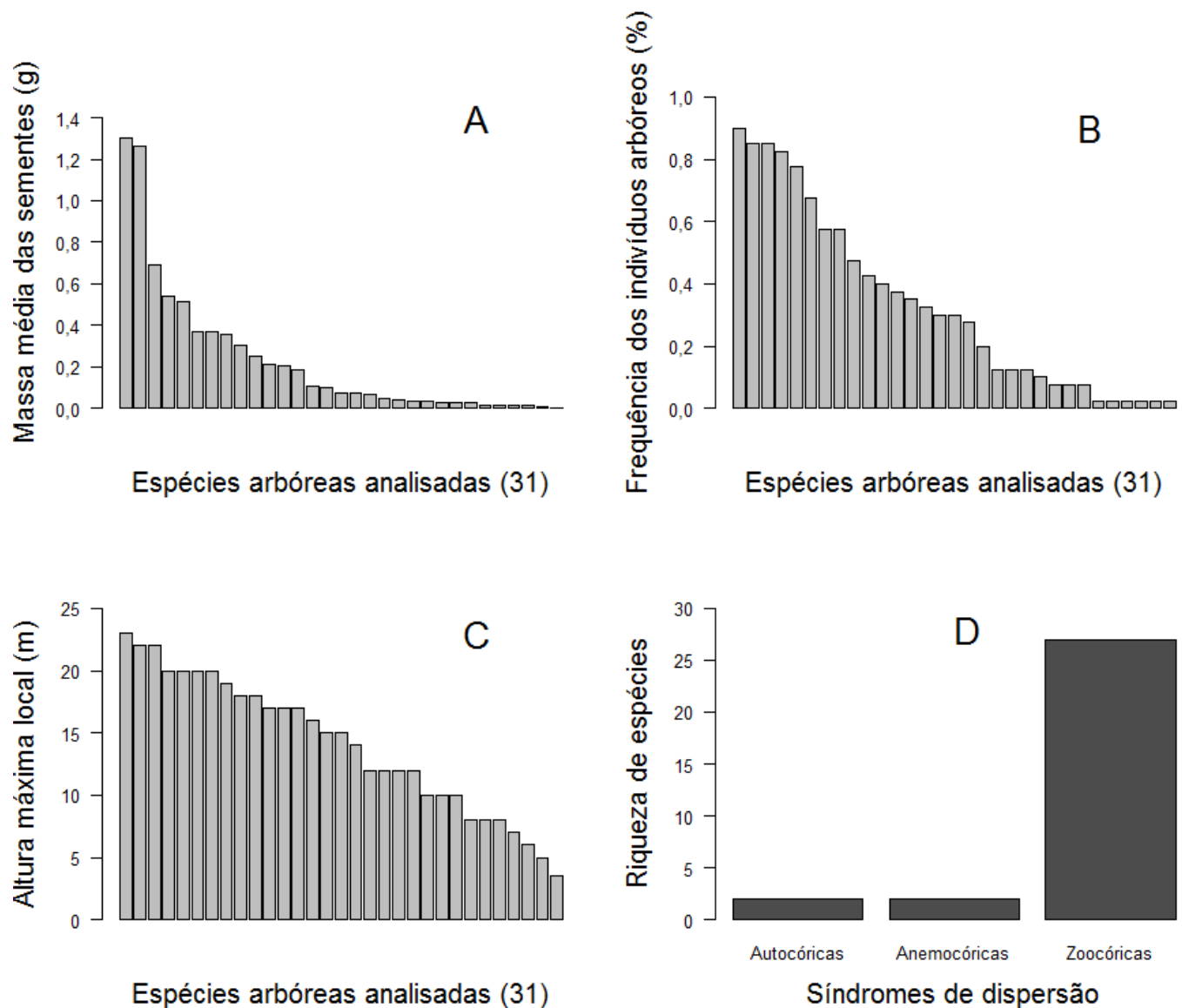

Figura 7. Distribuição dos valores das características relacionadas com o processo de dispersão de sementes para as espécies arbóreas analisadas em um fragmento da planície costeira do município de Caraguatatuba, Estado de São Paulo, Brasil

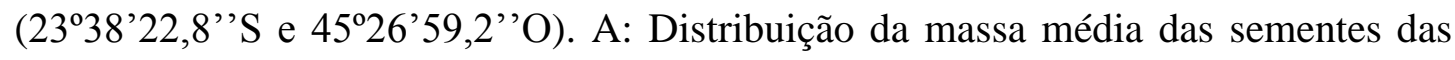
espécies arbóreas analisadas; B: Distribuição da frequência dos indivíduos arbóreos das espécies arbóreas analisadas; C: Distribuição da altura máxima das espécies arbóreas analisadas; D: Distribuição das espécies arbóreas analisadas em três categorias relacionadas à síndrome de dispersão da espécie (espécies autocóricas, anemocóricas e endozoocóricas). Nas figuras 7A-C, as espécies estão organizadas em ordem decrescente, logo a posição de cada espécie pode variar de acordo com a característica. 
Tabela 1. Coeficientes estimados para os fatores fixos dos modelos generalizados mistos selecionados para prever a limitação de dispersão espacial das espécies arbóreas em um fragmento da planície costeira do município de Caraguatatuba, Estado de São Paulo, Brasil. Os intervalos de confiança estão representados entre parênteses e aqueles que não incluem o zero estão destacados em negrito. A variável síndrome de dispersão (SD) não está representada abaixo porque não foi selecionada em nenhum dos modelos plausíveis. Modelo completo testado: LDe F + H + M + SD + H:M + H:SD + M:SD + F:H + F:M + F:SD + Efeitos aleatórios (Sp e A). Siglas: F = Frequência dos indivíduos arbóreos; H = Altura máxima local dos indivíduos arbóreos; $\mathrm{M}$ = Massa média das sementes; $\mathrm{SD}=$ Síndrome de dispersão; $\mathrm{Sp}=\mathrm{Espécie} ; \mathrm{A}=\mathrm{Ano}$ de amostragem.

\begin{tabular}{|c|c|c|c|c|c|}
\hline Modelo & Intercepto & $\begin{array}{c}\text { Frequência dos } \\
\text { indivíduos } \\
\text { arbóreos }\end{array}$ & $\begin{array}{l}\text { Altura máxima local } \\
\text { dos indivíduos } \\
\text { arbóreos }\end{array}$ & $\begin{array}{l}\text { Massa média } \\
\text { das sementes }\end{array}$ & $\triangle \mathrm{AICc}$ \\
\hline 1 & $\begin{array}{c}-0,1895 \\
(-0,2312 \text { a }-0,0269)\end{array}$ & $\begin{array}{c}-0,0992 \\
(-0,2312 \text { a } 0,0269)\end{array}$ & & & 0 \\
\hline 2 & $\begin{array}{c}-0,1890 \\
(-0,3176 \text { a }-0,0674)\end{array}$ & $\begin{array}{c}-0,0661 \\
(-0,2080 \text { a } 0,0714)\end{array}$ & $\begin{array}{c}-0,0737 \\
(-0,2146 \text { a } 0,0641)\end{array}$ & & 1,06 \\
\hline 3 & $\begin{array}{c}-0,1893 \\
(-0,3185 \text { a }-0,0670)\end{array}$ & $\begin{array}{c}-0,0962 \\
(-0,2254 \text { a } 0,0274)\end{array}$ & & $\begin{array}{c}0,0649 \\
(-0,0587 \text { a } 0,1931)\end{array}$ & 1,11 \\
\hline 4 & $\begin{array}{c}-0,1887 \\
(-0,3141 \text { a }-0,0704)\end{array}$ & $\begin{array}{c}-0,0604 \\
(-0,1989 \text { a } 0,0738)\end{array}$ & $\begin{array}{c}-0,0788 \\
(-0,2166 \text { a } 0,0555)\end{array}$ & $\begin{array}{c}0,0692 \\
(-0,0507 \text { a } 0,1940)\end{array}$ & 1,99 \\
\hline
\end{tabular}


Tabela 2. Coeficientes estimados para os fatores fixos dos modelos generalizados mistos selecionados para prever a limitação de dispersão temporal das espécies arbóreas em um fragmento da planície costeira do município de Caraguatatuba, Estado de São Paulo, Brasil. Os intervalos de confiança estão representados entre parênteses e aqueles que não incluem o zero estão destacados em negrito. A variável síndrome de dispersão (SD) não está representada abaixo porque não foi selecionada em nenhum dos modelos plausíveis. Modelo completo testado: LDt F $+\mathrm{H}+\mathrm{M}+\mathrm{SD}+\mathrm{H}: \mathrm{M}+\mathrm{H}: \mathrm{SD}+\mathrm{M}: \mathrm{SD}+\mathrm{F}: \mathrm{H}+\mathrm{F}: \mathrm{M}+\mathrm{F}: \mathrm{SD}+$ Efeitos aleatórios (Espécie e Ano de amostragem. Siglas: F = Frequência dos indivíduos arbóreos; $\mathrm{H}$ = Altura máxima local dos indivíduos arbóreos; $\mathrm{M}$ = Massa média das sementes; SD = Síndrome de dispersão.

\begin{tabular}{|c|c|c|c|c|c|}
\hline Modelo & Intercepto & $\begin{array}{l}\text { Massa média } \\
\text { das sementes }\end{array}$ & $\begin{array}{c}\text { Altura máxima local } \\
\text { dos indivíduos } \\
\text { adultos }\end{array}$ & $\begin{array}{l}\text { Frequência dos } \\
\text { Indivíduos } \\
\text { arbóreos }\end{array}$ & $\triangle \mathrm{AICc}$ \\
\hline 1 & $\begin{array}{c}-\mathbf{0 , 3 1 7 7} \\
(-0,4587 \text { a }-\mathbf{0 , 1 9 2 8 )}\end{array}$ & $\begin{array}{c}0,1147 \\
(-0,0106 \text { a } 0,2502)\end{array}$ & & & 0 \\
\hline 2 & $\begin{array}{c}-0,3176 \\
(-0,4550 \text { a }-\mathbf{0 , 1 9 6 2 )}\end{array}$ & $\begin{array}{c}0,1172 \\
(-0,0044 \text { a } 0,2497)\end{array}$ & $\begin{array}{c}-0,0801 \\
(-0,2121 \text { a } 0,0433)\end{array}$ & & 0,55 \\
\hline 3 & $\begin{array}{c}-0,3186 \\
(-0,4677 \text { a }-0,1855)\end{array}$ & & & & 1,07 \\
\hline 4 & $\begin{array}{c}-0,3179 \\
(-0,4585 \text { a }-0,1935)\end{array}$ & $\begin{array}{c}0,1128 \\
(-0,0123 \text { a } 0,2480)\end{array}$ & & $\begin{array}{c}-0,0376 \\
(-0,1722 \text { a } 0,0903)\end{array}$ & 1,88 \\
\hline 5 & $\begin{array}{c}-0,3185 \\
(-0,4646 \text { a }-0,1888)\end{array}$ & & $\begin{array}{c}-0,0769 \\
(-0,2173 \text { a } 0,0556)\end{array}$ & & 1,90 \\
\hline
\end{tabular}




\section{Discussão}

Neste estudo, as espécies arbóreas amostradas na chuva de sementes em uma comunidade da floresta de planície costeira apresentaram grandes proporções de espécies altamente limitadas espacial $(93,90 \%$; LDe entre $0,8 \quad 1,0)$ e temporalmente (82,93\%; LDt entre 0,8 e 1,0), em pelo menos um dos anos do estudo. Essas altas restrições espaciais e temporais na chegada de sementes apresentam um importante papel em mediar a coexistência das espécies. Além disso, a limitação de dispersão espacial das sementes foi fortemente relacionada com a limitação de dispersão temporal, indicando que espécies cujas sementes chegam a poucos locais também são espécies cujos períodos de frutificação são curtos. De maneira geral, três características das espécies influenciaram as limitações de dispersão espacial e temporal. O tamanho da semente apresentou uma tendência positiva em relação à limitação de dispersão, enquanto a altura máxima e a frequência de distribuição dos indivíduos arbóreos apresentaram uma tendência negativa. Entretanto, o estudo não constatou influência da síndrome de dispersão sobre as limitações de dispersão espacial e temporal, refutando, para o conjunto de espécies analisado, a hipótese de que as espécies dispersas por animais em geral apresentariam menores limitações de dispersão espacial e temporal.

Considerando as informações obtidas a partir da distribuição temporal da chuva de sementes, observou-se um pico na quantidade de sementes coletadas entre os meses de fevereiro e março, enquanto o número de espécies se manteve constante ao longo do ano. Outros estudos avaliaram a fenologia da produção de frutos (MORELLATO et al., 2000; TALORA \& MORELLATO, 2000; MARQUES \& OLIVEIRA, 2004; STAGGEMEIER \& MORELLATO, 2011) e da chegada de 
sementes em ambientes tropicais da planície costeira do Sudeste e Sul do Brasil (MARQUES \& OLIVEIRA, 2008). Em geral, o pico de produção e chegada de sementes ocorreu na mesma época, ou seja, nos meses mais úmidos do ano. Entretanto, nesses trabalhos citados, em geral, houve um pico na riqueza de espécies nos meses mais secos do ano, mas em um deles, realizado na floresta de planície costeira da região Sul do país, o pico de riqueza de espécies ocorreu nos meses mais úmidos (MARQUES \& OLIVEIRA, 2004). O padrão encontrado na área de estudo mostra que, em média, o número de espécies frutificando na área em cada mês corresponde a $16 \%$ do total de espécies amostradas na chuva de sementes. Então, considerando que a região estudada apresenta poucas variações climáticas ao longo do ano, esses resultados sugerem que o período reprodutivo de algumas espécies arbóreas pode ter sido deslocado ou, ainda, espécies que apresentavam pico reprodutivo em períodos diferentes conseguiram se estabelecer predominantemente nessa comunidade. Essa estratégia sugere a importância da limitação de dispersão temporal principalmente em ambientes expostos à condições climáticas mais estáveis temporalmente.

A limitação de dispersão espacial das sementes de espécies arbóreas nesta comunidade da planície costeira foi altamente correlacionada com a limitação de dispersão temporal. Entretanto, foi observado que as espécies altamente limitadas espacialmente nem sempre eram altamente limitadas temporalmente, sugerindo que as espécies da comunidade podem apresentar estratégias distintas que permitam a coexistência e manutenção das espécies na comunidade. As espécies altamente limitadas espacialmente (LDe entre 0,8 a 1,0), mas pouco limitadas temporalmente (LDt entre 0,0 e 0,4), possivelmente apresentam adultos distribuídos em ambientes com condições específicas, tornando a chegada de sementes mais restrita a 
determinados locais, mas a produção de frutos e sementes ocorrendo por um período de tempo menos restrito. $\mathrm{Na}$ área de estudo, apenas 6,45\% das espécies analisadas apresentam esse padrão, dentre elas a espécie Hyeronima alchorneoides. Essa estratégia poderia ser esperada para espécies pioneiras que produzem muitas sementes ao longo do ano, mas são pouco abundantes e mal distribuídas na comunidade de indivíduos adultos (MUHANGUZI \& IPULET, 2012).

Por outro lado, as espécies altamente limitadas temporalmente sempre apresentaram alta limitação espacial, representando um grupo de espécies que concentram a produção de frutos em poucos meses e cujas sementes não chegam a muitos locais. Dentre essas espécies arbóreas, existem aquelas que apresentam esse padrão possivelmente porque são espécies raras e pouco distribuídas na comunidade e, também, investem menos na produção massiva de frutos. Essa estratégia é frequentemente observada em espécies que produzem sementes grandes, que provêm energia suficiente para que a plântula se desenvolva mesmo em ambientes com poucos recursos e podem, portanto, apresentar maior habilidade competitiva (MOLES \& WESTOBY, 2004). Na área de estudo, essas características foram observadas em 9,68\% das espécies arbóreas analisadas. A baixa abundância e frequência populacional dessas potenciais melhores competidoras, juntamente com as altas limitações de dispersão espacial e temporal, permitem que outras espécies com menor habilidade competitiva se mantenham na comunidade.

Considerando a alta correlação observada entre limitação de dispersão espacial e temporal, seria esperado que algumas espécies apresentassem simultaneamente baixa limitação espacial e temporal. Na área de estudo, apenas uma espécie apresentou esse padrão, Coussapoa microcarpa. A chegada de sementes dessa espécie à maioria dos locais amostrados e durante o ano inteiro são características esperadas 
para espécies colonizadoras. Considerando as baixas limitações de dispersão da espécie, caso ela interagisse localmente com muitas outras espécies e as plântulas apresentassem alta habilidade competitiva, provavelmente $C$. microcarpa seria uma das espécies dominantes na comunidade. Entretanto, a densidade populacional dessa espécie na área amostrada corresponde a 35 indivíduos/ha, um valor 12 vezes menor do que a espécie mais abundante na área, Diospyros brasiliensis. Dessa maneira, os resultados encontrados sugerem que $C$. microcarpa seja uma espécie colonizadora com baixa habilidade competitiva e que a estratégia apresentada por ela seja importante para que ela persista em longo prazo na comunidade.

Apesar do exemplo acima, a maioria das espécies arbóreas analisadas foi altamente limitada espacialmente $(90,32 \%$; LDe entre 0,8 e 1,0$)$ e temporalmente (70,97\%; LDt entre 0,8 e 1,0) em pelo menos um dos anos do estudo. Alguns trabalhos compilaram informações sobre limitação de dispersão espacial das sementes (NORDEN et al., 2009; DU et al., 2011) obtidas a partir de experimentos com adição de sementes em diversas comunidades (TURNBULL et al., 2000; MOLES \& WESTOBY, 2002) e, também foram realizadas, meta-análises para avaliar o efeito da limitação de dispersão sobre o posterior estabelecimento de plântulas (CLARK et al., 2007). Assim como na comunidade estudada, esses trabalhos mostram que a limitação de dispersão das sementes é frequente em comunidades vegetais, o que sugere a importância do mecanismo de limitação de dispersão, espacial ou temporal, para a manutenção da diversidade em comunidades vegetais.

No que se refere às características que influenciaram a limitação de dispersão espacial das sementes de espécies arbóreas da comunidade estudada, a frequência de distribuição dos indivíduos adultos apresentou uma tendência negativa em relação à limitação de dispersão espacial. Entretanto, o efeito desse fator foi mínimo e incerto e, 
dessa forma, a distribuição de adultos não parece ser tão importante conforme esperado. Inicialmente, era esperado que a chegada das sementes no espaço pudesse ser prevista majoritariamente pela frequência de distribuição dos indivíduos adultos na comunidade. Pelo método de amostragem utilizado, a chegada de sementes deveria estar fortemente relacionada às espécies mais frequentes, uma vez que os coletores teriam maior probabilidade de serem colocados próximos aos indivíduos dessas espécies. Entretanto, a frequência de distribuição de adultos pode não ter sido muito importante em função de outros fatores. Os indivíduos de uma população apresentam variações relacionadas às capacidades de produção de frutos e de dispersão (HERRERA, 1988). Dessa maneira, alguns indivíduos podem não ter se reproduzido ao longo dos três anos de estudo e/ou indivíduos diferentes podem ter se reproduzido em anos diferentes, tornando incerta a relação entre a frequência e a limitação de dispersão espacial a cada ano. Portanto, seria interessante verificar as diferenças na produção de frutos entre os indivíduos das espécies mais abundantes e frequentes da comunidade. Seria esperado que quanto maior a população e mais frequente a distribuição dos indivíduos adultos da espécie, maior a chance desses indivíduos se diferenciarem simplesmente por questões demográficas estocásticas (HAGUE \& ROUTMAN, 2016).

A limitação de dispersão espacial foi influenciada negativamente pela altura máxima local dos indivíduos arbóreos e esteve presente em dois modelos dos quatro selecionados. MARQUES \& BURSLEM (2015) encontraram a mesma relação entre altura máxima e limitação de dispersão espacial, enquanto outros trabalhos encontraram relação entre altura e capacidade de dispersão (MULLER-LANDAU et al., 2008; THOMSON et al. 2011). Na área de estudo, as sementes das espécies arbóreas em geral foram altamente limitadas espacialmente. Porém, as espécies que 
apresentaram limitação de dispersão espacial intermediária e baixa foram somente aquelas com altura máxima acima de $15 \mathrm{~m}$. Portanto, apesar da grande proporção de espécies altamente limitadas espacialmente, algumas espécies emergentes podem se dispersar para locais mais distantes.

Além das características que apresentam uma relação negativa com a limitação de dispersão espacial, o tamanho da semente teve uma influência positiva sobre a limitação de dispersão espacial e apareceu em dois dos quatro modelos selecionados. Muitos trabalhos comprovaram a relação positiva entre sementes pequenas e capacidade de dispersão (MULLER-LANDAU et al., 2008; LU et al., 2013; NORGHAUER \& NEWBERY, 2015) e alguns testaram a relação positiva entre o tamanho da semente e a limitação de dispersão espacial (MCEUEN et al., 2004; CLARK et al., 2007; CHEN et al., 2013; MARTEINSDÓTTIR, 2014; MARQUES \& BURSLEM, 2015). Os resultados do presente estudo constataram a importância do tamanho da semente para o processo de dispersão de sementes, no entanto, apesar da tendência ter sido positiva, a maioria das espécies apresentou alta limitação de dispersão espacial independente do tamanho da semente.

Em relação à limitação de dispersão temporal, o tamanho da semente apresentou uma relação positiva e esteve presente em três dos cinco modelos selecionados. Entretanto, na área de estudo, as espécies que possuem sementes pequenas apresentaram uma alta variação em relação à limitação de dispersão temporal. Conforme o tamanho da semente das espécies aumenta, essa variação diminui e para as espécies com as maiores sementes a limitação de dispersão temporal é sempre alta. Essa diferença possivelmente está relacionada ao gasto energético para a produção de frutos e sementes grandes. Diversos estudos empíricos dão suporte para a hipótese de que espécies que produzem sementes grandes devem produzí-las em 
menor quantidade, enquanto que espécies que produzem sementes pequenas conseguem produzí-las em grande número e/ou por um longo período de tempo (MOLES \& WESTOBY, 2006). Dessa maneira, as espécies com sementes pequenas, devido ao menor gasto energético, podem produzir sementes ao longo de um período maior e têm a chance de chegar a locais propícios ao seu desenvolvimento quando plântulas de outras espécies melhores competidoras ainda não se encontram estabelecidas.

A relação negativa entre a altura e a limitação de dispersão temporal também apresentou algumas incertezas, apesar dessa variável ter sido a segunda que mais apareceu nos modelos selecionados. Observou-se que a maioria das espécies produzem frutos e sementes em um curto período no ano. Entretanto, as espécies que produzem frutos durante vários meses são aquelas cuja altura máxima está acima de $15 \mathrm{~m}$. Considerando um ambiente florestal, as espécies potencialmente mais altas devem captar mais energia luminosa. Alguns trabalhos mostram que indivíduos mais expostos à luminosidade produzem mais frutos e apresentam menos sincronia temporal na produção de frutos (GALLOWAY \& BURGESS, 2012). Isso pode fazer com que as espécies emergentes dispersem suas sementes por períodos maiores de tempo.

A limitação de dispersão temporal foi influenciada pela frequência de distribuição dos indivíduos adultos, porém esta variável esteve presente em apenas um dos cinco modelos selecionados. $\mathrm{O}$ efeito da frequência pode ter sido bastante incerto possivelmente porque as condições microambientais ao longo da comunidade não devem ser tão diferentes a ponto de modificar significativamente o período de frutificação das espécies. MARQUES \& OLIVEIRA (2008) estudaram a fenologia da chuva de sementes e do estabelecimento de plântulas em áreas alagáveis e não 
alagáveis de uma floresta na planície costeira do Sul do país e não encontraram diferenças sazonais nos dois processos. Mesmo com diferenças consideráveis nas condições microambientais, o estudo não encontrou sazonalidade nos dois processos. $\mathrm{Na}$ área de estudo, em que as diferenças microambientais são menos drásticas, também não haveria variação suficiente para promover diferenças na fenologia da chuva de sementes. Dessa forma, as diferenças de microcondições na área de estudo possivelmente apresentam pouca influência sobre as variações temporais na chuva de sementes das espécies mais frequentes na comunidade.

Dentre as características relacionadas com o processo de dispersão de sementes que foram analisadas, a síndrome de dispersão foi a única que não influenciou as limitações de dispersão espacial e temporal. Possivelmente, a principal razão para que a síndrome de dispersão não tenha sido selecionada em nenhum dos modelos testados é a diferença no tamanho amostral entre os grupos. A alta proporção de espécies endozoocóricas é bastante recorrente em comunidades em florestas tropicais (JESUS et al., 2012; SHELDON \& NADKARNI, 2013), mas, além disso, muitas espécies anemocóricas e autocóricas não atenderam o critério de inclusão para as análises, reduzindo ainda mais o tamanho amostral nesses grupos. A baixa proporção de espécies anemocóricas pode ser o resultado de altos índices de pluviosidade e da ausência de períodos secos bem definidos na região do estudo (MORELLATO et al, 2000; MARQUES \& OLIVEIRA, 2008). Devido à alta proporção de espécies endozoocóricas amostradas na chuva de sementes (79,27\%), futuramente seria interessante investigar porque essas espécies em geral foram altamente limitadas.

A ausência de potenciais dispersores na comunidade pode fazer com que as espécies se tornem mais limitadas espacialmente. Na área de estudo, foi realizado um 
levantamento da avifauna e a proporção de espécies frugívoras potencialmente dispersoras foi 27,17\% (ANEXO 5). Segundo alguns trabalhos relacionados com grupos funcionais alimentares em aves, a proporção de aves frugívoras amostrada na área de estudo corresponde à proporção de algumas áreas florestais tropicais (CAVERZERE et al., 2012; SEKERCIOGLU, 2012). Portanto, essa não deve ser a explicação para a alta limitação de dispersão espacial. Por outro lado, a alta limitação de dispersão das espécies endozoocóricas pode ser ocasionada pelo comportamento de remoção dos frutos por alguns dos animais dispersores, resultando em um padrão de chegada de sementes agregado (WENNY, 2001). Esse padrão agregado limita a dispersão das sementes para outros locais em que elas poderiam se estabelecer, e assim alguns animais podem aumentar a limitação de dispersão espacial dessas espécies.

Apesar de terem sido selecionadas três dentre as quatro características analisadas (tamanho da semente, altura máxima e a frequência de distribuição dos indivíduos adultos), as relações encontradas foram inconclusivas. Talvez existam outras características que possam influenciar a limitação de dispersão espacial e temporal das sementes. MARQUES \& BURSLEM (2015) encontraram que a abundância das sementes se relaciona negativamente com a limitação de dispersão espacial. Entretanto, utilizar os dados de abundância de sementes provenientes da amostragem da chuva de sementes a fim de estimar a produção de frutos não é muito significativo. Afinal, as sementes coletadas na chuva de sementes já passaram por um processo de dispersão anterior e a quantidade de frutos sendo produzido na população pode ser muito maior. Porém, os dados de abundância podem ser interessantes para se estimar curvas de distribuição de sementes a partir da localização dos indivíduos 
reprodutivos. Portanto, os dados de abundância de sementes podem ser muito interessantes em estudos com delineamento amostral espacialmente explícito.

Ainda que existam incertezas na relação entre as características selecionadas e as limitações de dispersão espacial e temporal, os resultados do estudo apresentam tendências constatadas anteriormente na literatura, reforçando o conhecimento acerca do mecanismo de limitação de dispersão espacial. Sob outra perspectiva, amplia os conhecimentos disponíveis sobre a distribuição temporal da chegada de sementes em comunidades arbóreas tropicais. Futuramente, seria interessante avaliar se o mecanismo de limitação de dispersão (espacial e temporal) contribui de fato para a coexistência das espécies. MCEUEN e colaboradores (2004) testaram, em uma floresta temperada, a probabilidade de encontro de uma espécie com evidências de limitação de dispersão espacial com outra não limitada. Os autores corroboraram a hipótese de que alta limitação de dispersão espacial reduzem as chances de encontro com outras espécies. Dessa forma, seria interessante testar as mesmas questões abordadas por MCEUEN e colaboradores (2004) em comunidades arbóreas tropicais e também considerar as distribuições temporais da chuva de sementes. Possivelmente, se os mecanismos de limitação de dispersão espacial e temporal são importantes para a coexistência das espécies na comunidade local, seria esperado que as sementes de espécies mais limitadas fossem menos encontradas ocorrendo com outras espécies nos locais e períodos em que são dispersas.

A principal vantagem do mecanismo de limitação de dispersão é a redução da competição entre espécies com habilidades competitivas muito diferentes (HURTT \& PACALA, 1995). Entretanto, essas ideias contrapõem as teorias de JANZEN (1970)CONNELL (1971) que indicam os mecanismos de dispersão eficientes de sementes como uma forma de minimizar a competição intraespecífica. A importância relativa 
dos mecanismos de dispersão e de limitação de dispersão para a manutenção da diversidade em comunidades deveria ser estudada para avaliar em quais situações ou para quais conjuntos de espécies a coexistência é mediada pela ausência das interações intraespecíficas ou interespecíficas. Dessa maneira, futuramente seria interessante investigar se a taxa de encontro com outras espécies é reduzida em espécies altamente limitadas espacial e temporalmente e se, por outro lado, as taxas de encontro com indivíduos da mesma espécie aumentam e qual o efeito disso para a riqueza de espécies na comunidade. 


\section{Referências Bibliográficas}

ADLER, G. H. \& KIELPINSKI, K. A. 2000. Reproductive phenology of a tropical canopy tree, Spondias mombin. Biotropica 32(4a): 686-692.

AGOSTINELLI, C. \& LUND, U. (2013). R package 'circular': Circular Statistics (version 0.47). URL https://r-forge.r-project.org/projects/circular/

BARTON, K. (2016). MuMIn: Multi-Model Inference. R package version 1.15.6. https://CRAN.R-project.org/package=MuMIn

BATES, D., MAECHLER, M., BOLKER, B. \& WALKER, S. (2015). Fitting Linear Mixed-Effects Models Using lme4. Journal of Statistical Software, 67(1), 148. doi:10.18637/jss.v067.i01.

BOLKER, B.M., PACALA, S.W. \& NEUHAUSER, C. 2003. Spatial Dynamics in Model Plant Communities: What Do We Really Know? The American Naturalist, 162:135-148.

BOLKER, B. \& R DEVELOPMENT CORE TEAM (2016). bbmle: Tools for General Maximum Likelihood Estimation. $\mathrm{R}$ package version 1.0.18. https://CRAN.R-project.org/package=bbmle

BURNHAM, K. P. \& ANDERSON, D. R. Model selection and multimodel inference: A practical information-theoretic approach. 2. ed. New York: SpringerVerlag, 2002.

CAVARZERE, V., MARCONDES, R.S., MORAES, G.P. \& DONATELLI, R. J. 2012. Comparação quantitativa da comunidade de aves de um fragmento de floresta semidecidual do interior do Estado de São Paulo em intervalo de 30 anos. Iheringia, Série Zoologia, Porto Alegre 102: 384-393. 
CHEN, L., WANG,L., BAIKETUERHAN, Y., ZHANG, C., ZHAO, X. \& GADOW, K. 2013. Seed dispersal and seedling recruitment of trees at different successional stages in a temperate forest in northeastern China. Journal of Plant Ecology 1-10.

CHESSON, P. 2000. Mecanisms of maintenance of species diversity. Annual review of Ecology, Evolution and Systematics 31:343-366.

CLARK, C.J., POULSEN, J.R., LEVEY, D.J. \& OSENBERG, C. W. 2007. Are Plant Populations Seed Limited? A Critique and Meta-Analysis of Seed Addition Experiments. The American Naturalist 170:128-142.

CORTÉS-FLORES, J., ANDRESEN, E., CORNEJO-TENORIO, G. \& IBARRA-MANRÍQUEZ, G. 2003. Fruiting phenology of seed dispersal syndromes in a Mexican Neotropical temperate forest. Forest Ecology and Management 289: 445454.

DALLING, J.W., MULLER-LANDAU, H.C., WRIGHT, S.J. \& HUBBELL, S. P. 2002. Role of Dispersal in the Recruitment Limitation of Neotropical Pioneer Species. Journal of Ecology 90: 714-727.

DELERUE, F., GONZALEZ, M., ATLAN, A., PELLERIN, S. \& AUGUSTO, L. 2013. Plasticity of reproductive allocation of a woody species (Ulex europaeus) in response to variation in resource availability. Annals of Forest Science, 70: 219-228.

DU,Y., MI, X. \& MA, K. 2012. Comparison of seed rain and seed limitation between community understory and gaps in a subtropical evergreen forest. Acta Oecologica, 44:11-19.

FERREIRA, F.S. Análise da influência das propriedades físicas do solo na deflagração dos escorregamentos translacionais rasos na Serra do Mar (SP). 2013. 112 
f. Dissertação (Mestrado em Geografia Física) - Departamento de Geografia, Faculdade de Filosofia, Letras e Ciências Humanas Universidade de São Paulo.

FILE, A.L., MURPHY, G.P. \& DUDLEY, S.A. 2011. Fitness consequences of plants growing with siblings: reconciling kin selection, niche partitioning and competitive ability. Proceedings of the royal society. doi:10.1098/rspb.2011.1995

FLORES-MORENO, H., THOMSON, F.J., WARTON, D.I. \& MOLES, A. T. 2013. Are Introduced Species Better Dispersers Than Native Species? A Global Comparative Study of Seed Dispersal Distance. PLoS ONE 8 (6): e6854.

GALLOWAY, L.F. \& BURGESS, K.S. 2012. Artificial selection on flowering time: influence on reproductive phenology across natural light environments. Journal of Ecology 100: 852-861.

GAUSE, G.F. 1937. Experimental populations of microscopic organisms. Ecology, 18: 173-179.

GIACOMINI, H.C. 2007. Os mecanismos de coexistência de espécies como vistos pela teoria ecológica. Oecologia Brasiliensis, 11: 521-543.

GREGORY, H.A. \& KIELPINSKI, K.A. Reproductive Phenology of a Tropical Canopy Tree, Spondias mombin. BIOTROPICA, 32:686-692.

GRIZ, L.M.S. \& MACHADO, I.C.S. 2001. Fruiting phenology and seed dispersal syndromes in caatinga, a tropical dry forest in the northeast of Brazil. Journal of Tropical Ecology 17: 303-321.

GRUEBER, C.E., NAKAWA, S., LAWS, R.J. \& JAMIESON, I. G. 2011. Multimodel inference in ecology and evolution: challenges and solutions. Journal of Evolutionary Biology 24: 699-711.

HAGUE, M.T.J. \& ROUTMAN, E.J. 2016. Does population size affect genetic diversity? A test with sympatric lizard species. Heredity 116: 92-98. 
HERRERA, C.M. 1988. The fruiting ecology of Osyris quadripartita: Individual variation and evolutionary potential. Ecology 69: 233-249.

HILLERISLAMBERS, J., ADLER, P.B., HARPOLE, W.S. et al. 2012. Rethinking Community Assembly through the Lens of Coexistence Theory. The Annual Review of Ecology, Evolution, and Systematics, 43:227-48.

HOWE, H.F. \& SMALLWOOD, J. 1982. Ecology of Seed Dispersal. Annual Review of Ecology and Systematics 13: 201-228.

HUBBELL, S.P., FOSTER, R.B., ÕBRIEN, S.T., HARMS, K. E., CONDIT, R., WECHSLER, B., WRIGHT, S. J. \& LOODELAO, S. 1999. Light-Gap Disturbances, Recruitment Limitation, and Tree Diversity in a Neotropical Forest. Science, 283: 554-557.

HUBBELL, S.P. 2005. Neutral theory in community ecology and the hypothesis of functional equivalence. Functional Ecology, 19: 166-172.

HURTT, G.C. \& PACALA, S.W. 1995. The Consequences of recruitment Limitation Reconciling Chance History and Competitive Differences between Plants. Journal of Theoretical Biology, 176: 1-12.

INMAN-NARAHARI, F., OSTERTAG, R., CORDELL, S., GIARDINA, C. P., NELSON-KAULA, K., SACK, L. 2013. Seedling recruitment factors in lowdiversity Hawaiian wet forest: towards global comparisons among tropical forests. Ecosphere, 4:1-19.

JACKSON, J.F. 1981. Seed Size as a Correlate of Temporal and Spatial Patterns of Seed Fall in a Neotropical Forest. Biotropica 13: 121-130.

JAZEN, D.H. 1970. Herbivores and the number of tree species in tropical forest. The American Naturalist 104: 501-524. 
JESUS, F.M., PIVELLO, V.R., MEIRELLES, S.T., FRANCO, G.A.D.C. \& METZGER, J.P. 2012. The importance of landscape structure for seed dispersal in rain forest fragments. Journal of Vegetation Science 23: 1126-1136.

KILKENNY, F.F. \& GALLOWAY L.F. 2008. Reproductive success in varying light environments: direct and indirect effects of light on plants and pollinators. Oecologia 155: 247-255.

KÖPPEN, W. 1948. Climatologia: con un estudio de los climas de la tierra. México, F. C. E.

LABTROP - GUIA DE PLANTAS DA RESTINGA. Disponível online: http://143.107.246.248/peic/guiaplanta.php

LARIOS, E. \& VENABLE, D.L. 2015. Maternal adjustment of offspring provisioning and the consequences for dispersal. Ecology, 96: 2771-2780.

LORENZI, H. Árvores Brasileiras . Nova Odessa: Editora Plantarum, 2009. Volume 1.

LORENZI, H. Árvores Brasileiras . Nova Odessa: Editora Plantarum, 2010. Volume 2.

LUO, Y., HE, F. \& YU, S. 2013. Recruitment limitation of dominant tree species with varying seed masses in a subtropical evergreen broad-leaved forest. Community ecology 14: 189-195.

MARQUES, M.C.M. \& OLIVEIRA, P.E.A.M. 2004. Fenologia de espécies do dossel e do sub-bosque de duas Florestas de Restinga na Ilha do Mel, sul do Brasil. Revista Brasileira de Botânica, 27:713-723.

MARQUES, M.C.M. \& OLIVEIRA, P.E.A.M. 2008. Seasonal rhythms of seed rain and seedling emergence in two tropical rain forests in southern Brazil. Plant Biology 10: 596-603. 
MARQUES, M.C.M. \& BURSLEM, DAVID F.R.P. 2015. Multiple stage recruitment limitation and density dependence effects in two tropical forests. Plant Ecology 216: 1243-1255.

MARTEINSDOTTIR, B. 2014. Seed Rain and Seed Bank Reveal that Seed Limitation Strongly Influences Plant Community Assembly in Grasslands. PLoS ONE 9: e103352.

MARTÍNEZ-GARZA， C., OSORIO-BERISTAIN， M., VALENZUELAGALVÁN, D. \& NICOLÁS-MEDINA, A. 2011. Intra and inter-annual variation in seed rain in a secondary dry tropical forest excluded from chronic disturbance. Forest Ecology and Management 262:2207-2218.

MARTINS, S. E., ROSSI, L., SAMPAIO, P. S. P. \& MAGENTA, M. A. G. 2008. Caracterização florística de comunidades vegetais de restinga em Bertioga, SP, Brasil. Acta Botanica Brasileira 22(1): 249-274.

MCEUEN, A.B. \& CURRAN, L.M. 2004. Seed dispersal and recruitment limitation across spatial scales in temperate forest fragments. Ecology 85: 507-518.

MOLES, A.T. \& WESTOBY, M. 2002. Seed addition experiments are more likely to increase recruitment in larger-seeded species. OIKOS 99: 241-248.

MOLES, A. T. \& WESTOBY, M. 2004. Seedling survival and seed size: a synthesis of the literature. Journal of Ecology 92: 372-383.

MOLES, A. T. \& WESTOBY, M. 2006. Seed size and plant strategy across the whole life cycle. Oikos 113: 91-105.

MORELlATO, L. P. C., TALORA, D. C., TAKAHASI, A., BENCKE, C. C., ROMERA, E. C. \& ZIPPARRO, V. B. 2000. Phenology of Atlantic rain forest trees: A comparative study. Biotropica 32(4): 811-823. 
MORO, M. F. \& MARTINS, F. R. Métodos de levantamento do componente arbóreo-arbustivo. In: FELFILI et al. Fitossociologia no Brasil: métodos e estudos de casos: volume I. Viçosa: UFV, 2011. cap. 6, p.174-212.

MULLER-LANDAU, H. C., WRIGHT, S. J., CALDERÕN, O., CONDIT, R. \& HUBBELL, S. P. 2008. Interspecific variation in primary seed dispersal in a tropical forest. Journal of Ecology 96: 653-667.

MOUQUET, N. \& LOREAU, M. 2002. Coexistence in metacommunities: The regional similarity hypothesis. The American Naturalist 159(4):420-426.

MUHANGUZI, H. D. R. \& IPULET, P. 2011. Fruiting phenology of fig trees in Kalinzu Forest, Uganda. African Journal od Ecology 50: 90-101.

NADIA, T. L., MORELLATO, L. P. C. \& MACHADO, I. C. 2012. Reproductive phenology of a northeast Brazilian mangrove community: Environmental and biotic constraints. Flora 207: 682-692.

NATHAN, R. \& MULLER-LANDAU, H. C. 2000. Spatial patterns of seed dispersal, their determinants and consequences for recruitment. Trends in Ecology and Evolution 15(7):278-285.

NORDEN, N., CHAVE, J., BELBENOIT, P., CAUBÈRE, A., CHÂTELET, P., FORGET, P. M., RIÉRA, B., VIERS, J. \& THÉBAUD, C. 2009. Interspecific variation in seedling responses to seed limitation and habitat conditions for 14 Neotropical woody species. Journal od Ecology 97: 186-197.

NORGHAUER, J. M. \& NEWBERRY, D. M. 2015. Tree size and fecundity influence ballistic seed dispersal of two dominant mast-fruiting species in a tropical rain forest. Forest ecology and management 338: 100-113. 
OTÁROLA, M. F., SAZIMA, M. \& SOLFERINI, V. N. 2013. Tree size and its relationship with flowering phenology and reproductive output in Wild Nutmeg trees. Ecology and Evolution 3(10): 3536-3544.

PALMER, M. W. 1994. Variation in species richness: towards a unification of hypotheses. Folia Geobotanica Phytotaxonomica 29: 511-530.

PESSOA, M. S., VLEESCHOUWER, K. M., TALORA, D. C., ROCHA, L. \& AMORIM, A. M. A. 2006. Reproductive phenology of Miconia mirabilis (Melastomataceae) within three distinct physiognomies of Atlantic forest, Bahia, Brazil. Biota Neotropica 12(2): 49-56.

PIRES, J. P. A., SILVA, A. G. \& FREITAS, L. 2013. Plant size, flowering synchrony and edge effects: What, how and where they affect the reproductive success of a Neotropical tree species. Austral Ecology, doi:10.1111/aec.12082.

PRIMACK, R. B. 1987. Relationships among flowers, fruits and seeds. Annual review of Ecology, Evolution and Systematics 18: 409-430.

R CORE TEAM (2016). R: A language and environment for statistical computing. $\mathrm{R}$ Foundation for Statistical Computing, Vienna, Austria. URL https://www.R-project.org/.

REZNIK, G., PIRES, J. P. A. \& FREITAS, L. 2012. Efeitos de bordas lineares na fenologia de espécies arbóreas zoocóricas em um remanescente de Mata Atlântica. Acta Botanica Brasilica 26(1): 65-73.

SEKERCIOGLU, C. H. 2012. Bird functional diversity and ecosystem services in tropical forests, agroforests and agricultural areas. Journal of Ornithology 153 
SHELDON, K. S. \& NADKARNI, N. M. 2013. Spatial and temporal variation of seed rain in the canopy and on the ground of a Tropical cloud forest. Biotropica 45(5): 549-556.

SMITHSONIAN TROPICAL RESEARCH INSTITUTE - PLANT IMAGE DATABASE.Disponívelonline:http://www.stri.si.edu/sites/esp/tesp/plant_images_a.h tm

STAGGEMEIER, V. G. \& MORELLATO, L. P. C. 2011. Reproductive phenology of coastal plain forest vegetation: comparisons from seashore to foothills. International journal of biometeorology 55: 843-854.

SELWYN, M. A. \& PARTHASARATHY, N. 2006. Fruiting phenology in a tropical dry evergreen forest on the Coromandel coast of India in relation to plant lifeforms, physiognomies groups, dispersal modes, and climatic constraints. Flora 202: 371-382.

SILVERTOWN, J. 2004. Plant coexistence and the niche. Trends in ecology and evolution 19(11): 605-611.

SOUZA, C. R. G., LOPES, E. A. \& MOREIRA, M. G. 2009. Coastal plain and low-medium slope sub-biomes: A nem approach based on native vegetationquaternary unit-soil associations. Brazilian jornal of biology.

SOUZA, J. T., FERRAZ, E. M. N., ALBUQUERQUE, U. P. \& ARAÚJO, E. L. 2013. Does proximity to a mature forest contribute to the seed rain and recovery of an abandoned agriculture área in a semiarid climate? Plant biology 16: 748-756.

SUN, C., KAPLIN, B. A., KRISTENSEN, K. A., MUNYALIGOGA, V., MVUKIYUMWAMI, J., KAJONDO, K. K. \& MOERMOND, T. C. 1996. Tree phenology in a tropical montane forest in Rwanda. Association for Tropical Biology and Conservation 28(4): 668-681. 
TALORA, D. C. \& MORELlATO, P. C. 2000. Fenologia de espécies arbóreas em floresta de planície litorânea do sudeste do Brasil. Revista Brasileira Botânica 23(1): 13-26.

TAMME, R., GÖTZENBERGER, L., ZOBEL, M., BULLOCK, J. M., HOOFTMAN, D. A. P., KAASIK, A. \& PÄRTEL, M. 2014. Predicting species' maximum dispersal distances from simple plant traits. Ecology 95(2): 505-513.

THOMSON, F. J., MOLES, A. T., AULD, T. D. \& KINGSFORD, R. T. 2011. Seed dispersal distance is more strongly correlated with plant height than with seed mass. Journal of Ecology 99: 1299-1307.

TILMAN, D. 2004. Niche trade-offs, neutrality, and community structure: A stochasticy theory of resource competition, invasion, and community assemble. Proceedings of the National Academy of Sciences 101(30):10854-10861.

TURNBULl, L. A., CRAWLEY, M. J. \& REES, M. 2000. Are plant populations seed-limited? A review of seed sowing experiments. Oikos $\quad 88$ : 225238.

VAN DER PIJL, L. Principles of dispersal in higher plants. 2. ed. Berlim: Springer-Verlag, 1972.

VELLEND, M. 2010. Conceptual syntheses in community ecology. The quartely review of biology 85(2):183-206.

VOGADO, N. O., CAMARGO, M. G. G., LOCOSSELlI, G. M. \& MORELLATO, L. P. C. 2016. Edge effects on the phenology of the guamirim, Myrcia guianensis (Myrtaceae), a cerrado tree, Brazil. Tropical Conservation Science 9(1): 291-312.

WANG, B. C. \& SMITH, T. B. 2002. Closing the seed dispersal loop. Trends in ecology and evolution 17(8): 379-385. 
WENNY, D. G. 2001. Advantages of seed dispersal: A re- evaluation directed dispersal. Evolutionary Ecology Research 3: 51-74.

WESTOBY, M., LEISHMAN, M. \& LORD, J. 1996. Comparative ecology of seed size and dispersal. The Royal Society 351: 1309-1318.

WRIGHT, S. J. 2002. Plant diversity in tropical forests: a review of mechanisms of species coexistence. Oecologia 130:1-14.

ZHANG, S. T., DU, G. Z. \& CHEN, J. K. 2004. Seed size in relation to phylogeny, growth form and longevity in a subalpine meadow on the east of the Tibetan Plateau. Folia Geobotanica 39: 129-142.

ZUUR, A.F., IENO E.N., WALKER, N.J., SAVELIEV, A.A. \& SMITH, G.M. Mixed effects models and extensions in ecology with R. 3. ed. London:Springer. 2009. 574p. 
Anexo 1

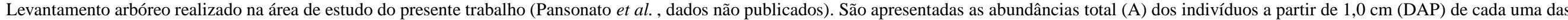
espécies e,também, em cada parcela amostrada. No presente estudo foram utilizados apenas os dados dos indivíduos acima de 4,8 cm (DAP). Legenda: A = Abundância de indivíduos arbóreos;

$\mathrm{F}=$ Frequência de ocorrência dos indivíduos arbóreos adultos.

Espécie/Parcela $\begin{array}{lllllllllllllllllllllllllllllllllllllllllllllll}\text { A } & \text { F } & 01 & 02 & 03 & 04 & 05 & 06 & 07 & 08 & 09 & 10 & 11 & 12 & 13 & 14 & 15 & 16 & 17 & 18 & 19 & 20 & 21 & 22 & 23 & 24 & 25 & 26 & 27 & 28 & 29 & 30 & 31 & 32 & 33 & 34 & 35 & 36 & 37 & 38 & 39 & 40 & & & & & \end{array}$ Aegiphila integrifolia Aiouea saligna 10,025

Albizia pedicellaris

Alchornea triplinervia

Amaioua intermedia

Anaxagorea dolichocarpa

Andira fraxinifolia

Aniba viridis

50,1

10,025

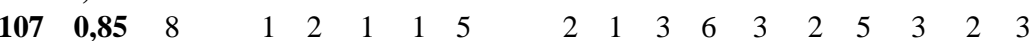
230

$370 \quad 0,475$

$50 \quad \mathbf{0 , 6} \quad 1$

Aparisthmium cordatum

88 0,475 2

$\begin{array}{ll}88 & 0,15\end{array}$

100,1

Attalea dubia

Bactris setosa

190,25

Blepharocalyx salicifoliu

Cabralea canjerana

Calophyllum brasiliense

Calyptranthes concinna

Calyptranthes lucida

Cecropia glaziovii

Cecropia pachystachya

Clethra scabra

Clidemia cf. urceolata

Cordia sellowiana

Cordiera cf. myrciifolia

Coussapoa microcarpa

Cryptocarya mandioccana

Cyathea atro

$\begin{array}{cc}75 & 0,45 \\ 4 & 0,075\end{array}$

10,025

$46 \quad 0,525$

10,025

140,275

$6 \quad 0,125$

$\begin{array}{lll}1 & \mathbf{0 , 0 2 5} & 1\end{array}$

$3 \quad 0,075$

10,025

10,025

120,125

520,6

10,025

$50 \quad 0,125$

Daphnopsis racemosa

Daphnopsis schwackeana

Dendropanax monogynu

Diospyros brasiliensis

Ecclinusa ramiflora

Endlicheria paniculata

Eriotheca pentaphylla

Eugenia astringens

30,05

10,025

$37 \quad 0,225$

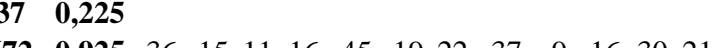

120,1

$49 \quad 0,55$

720,45

110,225

30,05

30,025

Eugenia cerasiflora $\begin{array}{llllllll}2 & 7 & 1 & & & 1 & 2\end{array}$ $\begin{array}{llllllll}23 & 2 & 7 & 3 & 17 & 9 & 20 & 1\end{array}$

$8+2$

21

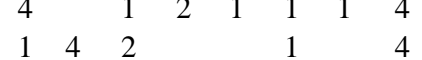

$\begin{array}{llllll}42 & 16 & 4 & 1 & 20\end{array}$

$\begin{array}{cccccccccccccccccc}2 & 2 & 1 & 1 & & 1 & & 1 & & 4 & 3 & 2 & & 1 & & 1 & 1 & 3 \\ 1 & 1 & & & 2 & & 1 & & 1 & 9 & & 2 & 1 & 4 & & & 11 & 2\end{array}$

$\begin{array}{llllll}4 & 3 & 3 & 2 & 3 & 1\end{array}$

6

1

$\begin{array}{lll}1 & 6 & 1\end{array}$

2

$$
\begin{array}{llll}
21 & 1 & & 1
\end{array}
$$$$
22
$$

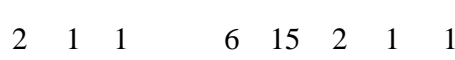

$\begin{array}{lllllllll}2 & 4 & & & & & & & \end{array}$

1

$\begin{array}{llllllll}1 & 2 & 1 & 1 & 1 & 7 & 1 & 4\end{array}$

$\begin{array}{lll}3 & 2 & 43\end{array}$

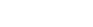

1

111

$\begin{array}{lllll}1 & 1 & 9 & & 4\end{array}$

$\begin{array}{llll}1 & 1 & 2 & 4\end{array}$

$\begin{array}{llllllllllllllllllllll}2 & 2 & 1 & 1 & 3 & 2 & 1 & 1 & & 3 & 1 & 2 & & 2 & & 3 & 7 & 8 & 15 & 1 & 2\end{array}$

1

1

1 
Eugenia melanogyna

Eugenia monosperma

Eugenia neoglomerata

Eugenia oblongata

Eugenia stigmatosa

Eugenia sulcata

10,025

1710,675

630,5

Euterpe edulis

Ficus enormis

Ficus gomelleira

Ficus insipida

Ficus pulchella

Garcinia gardneriana

Geonoma schottiana

Guapira hirsuta

Guapira opposita

Guarea macrophylla

Guatteria australis

Handroanthus albus

Handroanthus umbellatus

Heisteria silvianii

Huberia ovalifolia

Hyeronima alchorneoides

Hymenolobium janeirense

Ilex dumosa

Ilex pseudobuxus

Ilex theezans

Inga edulis

Inga sessilis

Inga striata

Jacaranda puberula

Lacistema lucidum

Ladenbergia hexandra

550,6

150,3

120,

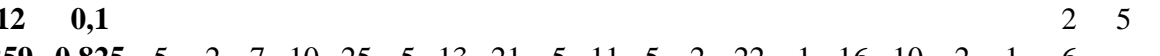

10,025

30,075

10,025

$3 \mathbf{0 , 0 7 5}$

90,15

$7 \quad 0,15$

60,125

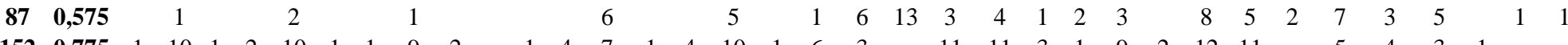

1520,775

$\begin{array}{cc}37 & \mathbf{0 , 4} \\ \mathbf{5} & \mathbf{0 , 1}\end{array}$

20,05

$57 \quad 0,55$

10,025

40,1

10,025

$\begin{array}{lll}7 & 0,15\end{array}$

$3 \quad 0,075$

$24 \quad 0,3$

20,05

$5 \quad 0,125$

30,05

320,375

10,025

30,025

20,025

$29 \quad 0,025$

Mabea piriri

Machaerium nyctitans

Manilkara subsericea

Marlierea claussenian

Marlierea racemosa

10,025

130,2

240,3

$17 \quad 0,2$

Marlierea tomentosa

110,175

Matayba intermedia

24 0,475

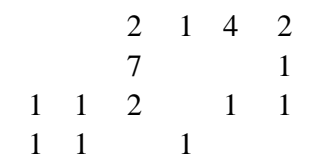

$5 \quad 1$

$\begin{array}{llll}3 & 4 & 20 & 2\end{array}$

$\begin{array}{llllllll}5 & 11 & 1 & 3 & 18 & 8 & 17 & 9\end{array}$

2

$\begin{array}{ll} & 1 \\ 1 & 1\end{array}$

$\begin{array}{lll}14 & 1\end{array}$

$\begin{array}{ll}2 & 1\end{array}$

$\begin{array}{llllll}1 & 1 & 3 & 4 & 6 & 7 \\ 1 & 2 & & & & 2\end{array}$

$\begin{array}{llllllll}10 & 11 & 4 & 1 & 5 & 7 & 10 & 10\end{array}$

89

12

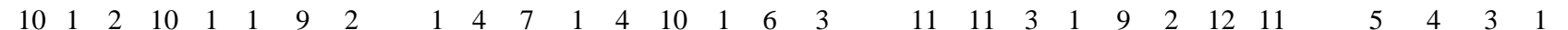

$\begin{array}{llll}1 & 1 & 2\end{array}$

1

$\begin{array}{rr} & 1 \\ & 1 \\ 1 & 1\end{array}$

1

(1)

1

29

$\begin{array}{llllll}2 & 1 & 1 & 1 & 1 & 2\end{array}$

1

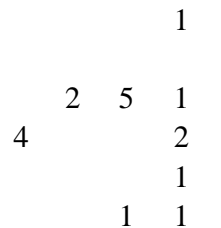

1
1
2

3 

\begin{tabular}{lllllllllllllllllllllllllllllllllllllllllllll} 
A & F & 01 & 02 & 03 & 04 & 05 & 06 & 07 & 08 & 09 & 10 & 11 & 12 & 13 & 14 & 15 & 16 & 17 & 18 & 19 & 20 & 21 & 22 & 23 & 24 & 25 & 26 & 27 & 28 & 29 & 30 & 31 & 32 & 33 & 34 & 35 & 36 & 37 & 38 & 39 & 40 \\
\hline
\end{tabular}

Maytenus gono

$\begin{array}{lll}\mathbf{A} & \mathbf{F} & \mathbf{0 , 1 7 5} \\ & \mathbf{0 , 0 2 5}\end{array}$

Miconia cf. cinnamomifolia $\mathbf{1} \mathbf{0 , 0 2 5}$

Miconia dodecandra

$\mathbf{0 , 0 2 5}$
$\mathbf{0 , 0 2 5}$

Miconia prasina

Miconia pusilliflora

Mollinedia cf. ovata

Mollinedia schottiana

30,05

$5 \quad 0,075$

$\begin{array}{lcc}5 & 5 & 0,1 \\ & 45 & 0,375\end{array}$

Myrcia glabra

Myrcia hexasticha

140,325

Myrcia hexasticha

30,05

110,175

$4 \quad 0,075$

310,325

Myrcia pubipetala

Myrcia spectabilis

Myrcia splendens

Myrsine coriacea

Myrsine guianensis

Myrsine venosa

Nectandra grandiflora

Nectandra oppositifolia

Ocotea aciphylla

Ocotea brachybotrya

Ocotea lanata

Ocotea mosenii

Ocotea pulchella

Ocotea venulosa

Oreopanax capitatus

Ormosia arborea

Ossaea sp.

Ouratea multiflora

Ouratea parviflora

Pera glabrata

Persea willdenovii

Pisonia sp.

Podocarpus sellowii

Posoqueria latifolia

Pouteria beaurepairei

Pouteria psammophila

Prunus myrtifolia

$\begin{array}{lll}72 & 0,7 & 4\end{array}$

$5 \quad 0,025$

$17 \quad 0,025$

$180,125 \quad 4$

10,025

$3 \quad \mathbf{0 , 0 7 5}$

10,025

$\begin{array}{llllllllllllllllllllllllllllllllllllllllllll}150 & \mathbf{0 , 8 7 5} & 43 & 2 & 2 & 3 & 6 & 3 & 1 & 3 & 4 & 2 & 1 & 6 & 1 & 11 & 1 & & 1 & 1 & 2 & & 3 & 1 & 1 & 2 & 1 & 1 & 2 & 8 & 1 & 10 & 3 & 15 & 1 & & 4 & 2 & 1 & 1\end{array}$

60,15

10,025

$3 \mathbf{0 , 0 7 5}$

140,25

$\begin{array}{lll}3 & \mathbf{0 , 0 5} & 2\end{array}$

120,225

10,025

80,125

30,075

10,025

$4 \quad 0,075 \quad 1$

$34 \quad 0,425$

10,025

$\begin{array}{llllll}33 & \mathbf{0 , 5} & 2 & 2 & 4 & 1\end{array}$

20,05

230,35

320,45

30,075

$4 \quad 0,075$

Psidium cattleianum

50,1

Psychotria cf. hastisepala

$5 \quad \mathbf{0 , 0 2 5} 5$ 
Espécie/Parcela

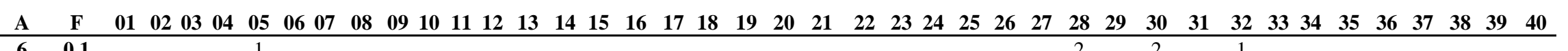

$\begin{array}{lll}\text { Psychotria hoffmannseggian } & \mathbf{6} & \mathbf{0 , 1}\end{array}$

Pterocarpus rohrii

Rudgea coriacea

10,025

Schefflera angustissima

Siparuna brasiliensis

Sloanea guianensis

$7 \quad 0,05$

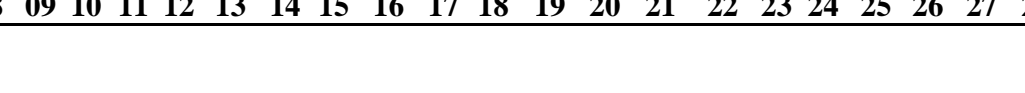

Sorocea cf. jureiana

Stylogyne lhotzkyana

Styrax glabratus

$1050,6 \quad 2 \quad 7$

$\begin{array}{llllll}159 & \mathbf{0 , 8 7 5} & 1 & 1 & 1 & 5\end{array}$

80,075

$\begin{array}{llll}1 & 1 & 3 & 2\end{array}$

$\begin{array}{lllllllllllllllllllll}6 & 5 & 1 & 2 & 8 & 4 & 2 & 3 & 3 & 4 & 6 & 5 & 1 & 4 & 5 & 11 & 3 & 5 & 10 & 9 & 11\end{array}$

$\begin{array}{lllll}6 & 2 & 12 & 9 & 7\end{array}$

Symplocos estrellensis

Syzygium jambos

Tabebuia cassinoides

Tabebuia sp.

$3 \quad 0,05$

$12 \quad 3 \quad 2$

30,05

$\begin{array}{lll}1 & \mathbf{0 , 0 2 5} \\ 3 & \mathbf{0 , 0 5} & 2\end{array}$

$1680,5 \quad 2$

10,025

Tapirira guianensis

Tibouchina pulchra

Tibouchina stenocarpa

Trichilia pallens

Vitex polygama

650,625

20,05

120,05

10,025

20,025

$17 \quad 0,125$

Xylopia langsdorfiana

Zanthoxylum rhoifolium

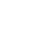




\section{Anexo 2}

Espécies amostradas na chuva de sementes ordenadas de forma decresciva pelo número de coletores em que foram encontradas ao longo dos três anos de estudo. Legendas: $\mathrm{AB}=$ Abundância de sementes; $\mathrm{NC}=$ Número de coletores; $\mathrm{LDe}=$ Limitação de dispersão espacial; $\mathrm{LDt}=\mathrm{Limitação} \mathrm{de} \mathrm{dispersão}$ temporal; F = Frequência de indivíduos arbóreos; $\mathrm{M}=$ Massa média das sementes; $\mathrm{SD}=$ Síndrome de dispersão; HL = Altura máxima local; Z = Zoocórica; Ane $=$ Anemocórica; Auto = Autocórica.

*Espécies na chuva de sementes que não foram amostradas no levantamento arbóreo.

®Espécies utilizadas na análise de correlação e na seleção de modelos

\begin{tabular}{|c|c|c|c|c|c|c|c|c|c|c|c|c|c|c|c|c|c|c|c|c|c|}
\hline \multirow{2}{*}{ Espécie } & \multirow{2}{*}{ Família } & \multicolumn{4}{|c|}{ Ano 1} & \multicolumn{4}{|c|}{ Ano 2} & \multicolumn{4}{|c|}{ Ano 3} & \multicolumn{4}{|c|}{ Total } & \multirow{2}{*}{ 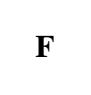 } & \multirow[t]{2}{*}{$\mathrm{M}$} & \multirow{2}{*}{ SD } & \multirow{2}{*}{ HL } \\
\hline & & $\mathbf{A B}$ & NC & LDE & LDT & $\mathbf{A B}$ & NC & LDE & LDT & $\mathbf{A B}$ & NC & LDE & LDT & $\mathbf{A B}$ & NC & LDE & LDT & & & & \\
\hline 1 Coussapoa microcarpa ${ }^{\circledR}$ & Urticaceae & 4285 & 39 & 0,025 & 0 & 2668 & 38 & 0,05 & 0 & 5608 & 38 & 0,05 & 0 & 12561 & 40 & 0 & 0 & 0,575 & 0,0014 & $\mathrm{Z}$ & 18 \\
\hline 2 Myrsine spp & Primulaceae & 249 & 33 & 0,175 & 0,25 & 118 & 28 & 0,3 & 0,5 & 164 & 28 & 0,275 & 0,25 & 531 & 37 & 0,075 & 0,278 & 0,175 & 0,0138 & $\mathrm{Z}$ & 15 \\
\hline 3 Alchornea triplinervia ${ }^{\circledR}$ & Euphorbiaceae & 27 & 15 & 0,65 & 0,75 & 24 & 13 & 0,675 & 0,583 & 46 & 18 & 0,55 & 0,667 & 97 & 28 & 0,3 & 0,667 & 0,85 & 0,0396 & $\mathrm{Z}$ & 20 \\
\hline 4 Schefflera angustissima ${ }^{\circledR}$ & Araliaceae & 316 & 18 & 0,55 & 0,25 & 215 & 18 & 0,55 & 0 & 278 & 14 & 0,65 & 0,333 & 809 & 26 & 0,35 & 0,194 & 0,575 & 0,0272 & $\mathrm{Z}$ & 18 \\
\hline 5 Nectandra oppositifolia ${ }^{\circledR}$ & Lauraceae & 13 & 6 & 0,925 & 0,75 & 101 & 18 & 0,55 & 0,583 & 157 & 19 & 0,525 & 0,583 & 271 & 24 & 0,4 & 0,639 & 0,825 & 0,5421 & $\mathrm{Z}$ & 22 \\
\hline 6 Cecropia spp & Urticaceae & 76 & 9 & 0,775 & 0,417 & 29 & 6 & 0,85 & 0,25 & 56 & 15 & 0,625 & 0,25 & 161 & 22 & 0,45 & 0,306 & 0,125 & 0,0009 & $\mathrm{Z}$ & 16 \\
\hline 7 Hymenolobium janeirense ${ }^{\circledR}$ & Fabaceae & 0 & 0 & 1 & 1 & 13 & 3 & 0,925 & 0,75 & 232 & 19 & 0,525 & 0,667 & 245 & 22 & 0,45 & 0,806 & 0,025 & 0,0495 & Ane & 15 \\
\hline 8 Ilex spp & Aquifoliaceae & 42 & 15 & 0,625 & 0,417 & 19 & 8 & 0,8 & 0,583 & 42 & 14 & 0,65 & 0,333 & 103 & 22 & 0,45 & 0,444 & 0,4 & 0,0063 & $\mathrm{Z}$ & 17 \\
\hline 9 Pera glabrata ${ }^{\circledR}$ & Peraceae & 52 & 18 & 0,55 & 0,667 & 10 & 7 & 0,825 & 0,667 & 42 & 16 & 0,6 & 0,5 & 104 & 22 & 0,45 & 0,611 & 0,325 & 0,0124 & $\mathrm{Z}$ & 19 \\
\hline 10 Geonoma schottiana ${ }^{\circledR}$ & Arecaceae & 40 & 8 & 0,8 & 0,5 & 116 & 4 & 0,9 & 0,5 & 34 & 8 & 0,8 & 0,5 & 190 & 16 & 0,6 & 0,5 & 0,075 & 0,0351 & $\mathrm{Z}$ & 5 \\
\hline 11 Inga sp & Fabaceae & 36 & 8 & 0,8 & 0,75 & 3 & 3 & 0,925 & 0,833 & 14 & 8 & 0,8 & 0,583 & 53 & 15 & 0,625 & 0,722 & & & $\mathrm{Z}$ & \\
\hline 12 Cupania/Matayba* & Sapindaceae & 18 & 12 & 0,7 & 0,833 & 6 & 4 & 0,9 & 0,833 & 3 & 2 & 0,95 & 0,833 & 27 & 14 & 0,65 & 0,833 & & & $\mathrm{Z}$ & \\
\hline 13 Laplacea fruticosa ${ }^{\circledR}$ & Theaceae & 16 & 7 & 0,825 & 0,333 & 28 & 7 & 0,825 & 0,667 & 10 & 8 & 0,8 & 0,667 & 54 & 13 & 0,675 & 0,556 & 0,025 & 0,0127 & Ane & 8 \\
\hline 14 Maprounea guianensis ${ }^{\circledR}$ & Euphorbiaceae & 29 & 9 & 0,775 & 0,667 & 153 & 8 & 0,8 & 0,583 & 359 & 3 & 0,925 & 0,5 & 541 & 13 & 0,675 & 0,583 & 0,125 & 0,0114 & Auto & 17 \\
\hline 15 Myrcia sp4 & Myrtaceae & 13 & 8 & 0,8 & 0,75 & 8 & 4 & 0,9 & 0,833 & 14 & 4 & 0,9 & 0,667 & 35 & 13 & 0,675 & 0,75 & & & $\mathrm{Z}$ & \\
\hline 16 Amaioua intermedia ${ }^{\circledR}$ & Rubiaceae & 259 & 10 & 0,75 & 0,583 & 0 & 0 & 1 & 1 & 7 & 4 & 0,9 & 0,75 & 266 & 12 & 0,7 & 0,778 & 0,3 & 0,0105 & $\mathrm{Z}$ & 12 \\
\hline 17 Calophyllum brasiliense ${ }^{\circledR}$ & Calophylaceae & 1 & 1 & 0,975 & 0,917 & 50 & 6 & 0,9 & 0,833 & 24 & 11 & 0,725 & 0,75 & 75 & 12 & 0,7 & 0,833 & 0,375 & 1.263 & $\mathrm{Z}$ & 22 \\
\hline 18 Matayba intermedia ${ }^{\circledR}$ & Sapindaceae & 41 & 9 & 0,775 & 0,75 & 211 & 7 & 0,825 & 0,833 & 14 & 6 & 0,85 & 0,833 & 266 & 12 & 0,7 & 0,806 & 0,425 & 0,1071 & $\mathrm{Z}$ & 20 \\
\hline 19 Ocotea pulchella ${ }^{\circledR}$ & Lauraceae & 4 & 4 & 0,9 & 0,667 & 6 & 6 & 0,85 & 0,833 & 2 & 2 & 0,95 & 0,833 & 12 & 10 & 0,75 & 0,778 & 0,025 & 0,0721 & $\mathrm{Z}$ & 12 \\
\hline 20 Guapira spp & Nyctaginaceae & 166 & 5 & 0,875 & 0,333 & 29 & 1 & 0,975 & 0,75 & 19 & 7 & 0,925 & 0,583 & 214 & 9 & 0,775 & 0,5 & 0,45 & 0,0364 & $\mathrm{Z}$ & 16 \\
\hline 21 Guarea macrophylla ${ }^{\circledR}$ & Meliaceae & 5 & 5 & 0,875 & 0,667 & 3 & 3 & 0,925 & 0,75 & 2 & 2 & 0,95 & 0,833 & 10 & 9 & 0,775 & 0,75 & 0,675 & 0,2034 & $\mathrm{Z}$ & 10 \\
\hline 22 Hyeronima alchorneoides ${ }^{\circledR}$ & Euphorbiaceae & 232 & 2 & 0,95 & 0,417 & 631 & 7 & 0,825 & 0,167 & 534 & 5 & 0,875 & 0,333 & 1397 & 9 & 0,775 & 0,306 & 0,075 & 0,0151 & $\mathrm{Z}$ & 17 \\
\hline
\end{tabular}




\begin{tabular}{|c|c|c|c|c|c|c|c|c|c|c|c|c|c|c|c|c|c|c|c|c|c|}
\hline \multirow{2}{*}{ Espécie } & \multirow{2}{*}{ Família } & \multicolumn{4}{|c|}{ Ano 1} & \multicolumn{4}{|c|}{ Ano 2} & \multicolumn{4}{|c|}{ Ano 3} & \multicolumn{4}{|c|}{ Total } & \multirow[t]{2}{*}{$\mathbf{F}$} & \multirow{2}{*}{$\mathbf{M}$} & \multirow{2}{*}{ SD } & \multirow{2}{*}{ HL } \\
\hline & & $\mathbf{A B}$ & NC & LDE & LDT & $\mathbf{A B}$ & NC & LDE & LDT & $\mathbf{A B}$ & NC & LDE & LDT & $\mathbf{A B}$ & NC & LDE & LDT & & & & \\
\hline 23 Anaxagorea dolichocarpa ${ }^{\circledR}$ & Annonaceae & 5 & 3 & 0,925 & 0,583 & 4 & 2 & 0,95 & 0,667 & 1 & 1 & 0,975 & 0,917 & 10 & 6 & 0,85 & 0,75 & 0,475 & 0,2481 & $\mathrm{Z}$ & 14 \\
\hline 24 Guatteria australis ${ }^{\circledR}$ & Annonaceae & 16 & 3 & 0,925 & 0,75 & 2 & 2 & 0,95 & 0,917 & 2 & 2 & 0,95 & 0,917 & 20 & 6 & 0,85 & 0,861 & 0,35 & 0,037 & $\mathrm{Z}$ & 12 \\
\hline 25 Heisteria silvianii ${ }^{\circledR}$ & Olacaceae & 0 & 0 & 1 & 1 & 0 & 0 & 1 & 1 & 6 & 6 & 0,85 & 0,75 & 6 & 6 & 0,85 & 0,917 & 0,4 & 0,2147 & $\mathrm{Z}$ & 8 \\
\hline 26 Sloanea guianensis ${ }^{\circledR}$ & Elaeocarpaceae & 79 & 6 & 0,85 & 0,833 & 0 & 0 & 1 & 1 & 0 & 0 & 1 & 1 & 79 & 6 & 0,85 & 0,944 & 0,85 & 0,0736 & $\mathrm{Z}$ & 17 \\
\hline 27 Dictyoloma vandellianum* & Rutaceae & 0 & 0 & 1 & 1 & 5 & 3 & 0,925 & 0,833 & 3 & 2 & 0,95 & 0,833 & 8 & 4 & 0,9 & 0,889 & & & Ane & \\
\hline 28 Euterpe edulis ${ }^{\circledR}$ & Arecaceae & 1 & 1 & 0,975 & 0,917 & 8 & 1 & 0,975 & 0,833 & 4 & 3 & 0,925 & 0,833 & 13 & 4 & 0,9 & 0,861 & 0,775 & 0,3044 & $\mathrm{Z}$ & 12 \\
\hline 29 Handroanthus/Tabebuia & Bignoniaceae & 0 & 0 & 1 & 1 & 6 & 4 & 0,9 & 0,75 & 0 & 0 & 1 & 1 & 6 & 4 & 0,9 & 0,917 & 0,5 & 0,0066 & Ane & 18 \\
\hline 30 Lauraceae & Lauraceae & 0 & 0 & 1 & 1 & 4 & 4 & 0,9 & 0,75 & 0 & 0 & 1 & 1 & 4 & 4 & 0,9 & 0,917 & & & $\mathrm{Z}$ & \\
\hline 31 Prunus myrtifolia $₫$ & Rosaceae & 1 & 1 & 0,975 & 0,917 & 6 & 3 & 0,925 & 0,833 & 2 & 1 & 0,975 & 0,917 & 9 & 4 & 0,9 & 0,889 & 0,075 & 0,3578 & $\mathrm{Z}$ & 15 \\
\hline 32 Solanum $\mathrm{spp}^{*}$ & Solanaceae & 1 & 1 & 0,975 & 0,917 & 0 & 0 & 1 & 1 & 5 & 3 & 0,925 & 0,75 & 6 & 4 & 0,9 & 0,889 & & & $\mathrm{Z}$ & \\
\hline 33 Diospyros brasiliensis ${ }^{\circledR}$ & Ebenaceae & 0 & 0 & 1 & 1 & 30 & 3 & 0,925 & 0,833 & 0 & 0 & 1 & 1 & 30 & 3 & 0,925 & 0,944 & 0,9 & 0,3692 & $\mathrm{Z}$ & 20 \\
\hline 34 Eugenia cerasiflora ${ }^{\circledR}$ & Myrtaceae & 1 & 1 & 0,975 & 0,917 & 4 & 2 & 0,95 & 0,833 & 0 & 0 & 1 & 1 & 5 & 3 & 0,925 & 0,917 & 0,025 & 1.300 & $\mathrm{Z}$ & 10 \\
\hline 35 Marlierea $\mathrm{sp}$ & Myrtaceae & 0 & 0 & 1 & 1 & 3 & 1 & 0,975 & 0,917 & 5 & 3 & 0,925 & 0,667 & 8 & 3 & 0,925 & 0,861 & & & $\mathrm{Z}$ & \\
\hline 36 Myrcia sp1 & Myrtaceae & 13 & 2 & 0,95 & 0,917 & 1 & 1 & 0,975 & 0,917 & 0 & 0 & 1 & 1 & 14 & 3 & 0,925 & 0,944 & & & $\mathrm{Z}$ & \\
\hline 37 Myrcia multiflora $®$ & Myrtaceae & 3 & 1 & 0,975 & 0,917 & 2 & 2 & 0,95 & 0,833 & 0 & 0 & 1 & 1 & 5 & 3 & 0,925 & 0,917 & 0,025 & 0,03 & $\mathrm{Z}$ & 7 \\
\hline 38 Stylogyne lhotzkyana ${ }^{\circledR}$ & Primulaceae & 5 & 2 & 0,95 & 0,833 & 1 & 1 & 0,975 & 0,917 & 0 & 0 & 1 & 1 & 6 & 3 & 0,925 & 0,917 & 0,275 & 0,0988 & $\mathrm{Z}$ & 6 \\
\hline 39 Calyptranthes sp & Myrtaceae & 6 & 1 & 0,975 & 0,917 & 3 & 1 & 0,975 & 0,917 & 0 & 0 & 1 & 1 & 9 & 2 & 0,95 & 0,944 & 0,175 & 0,0463 & $\mathrm{Z}$ & 10 \\
\hline 40 Daphnopsis spp & Thymelaeaceae & 0 & 0 & 1 & 1 & 0 & 0 & 1 & 1 & 2 & 2 & 0,95 & 0,833 & 2 & 2 & 0,95 & 0,944 & 0,025 & 0,1472 & $\mathrm{Z}$ & 7 \\
\hline 41 Eugenia $\mathrm{sp} 8$ & Myrtaceae & 0 & 0 & 1 & 1 & 28 & 2 & 0,95 & 0,75 & 0 & 0 & 1 & 1 & 29 & 2 & 0,95 & 0,917 & & & $\mathrm{Z}$ & \\
\hline 42 Inga sessilis ${ }^{\circledR}$ & Fabaceae & 57 & 1 & 0,975 & 0,833 & 5 & 1 & 0,975 & 0,917 & 0 & 0 & 1 & 1 & 62 & 2 & 0,95 & 0,917 & 0,1 & 0,1848 & $\mathrm{Z}$ & 20 \\
\hline 43 Manilkara subsericea ${ }^{\circledR}$ & Sapotaceae & 0 & 0 & 1 & 1 & 1 & 1 & 0,975 & 0,917 & 9 & 1 & 0,975 & 0,833 & 10 & 2 & 0,95 & 0,917 & 0,2 & 0,3686 & $\mathrm{Z}$ & 23 \\
\hline 44 Piptadenia gonoacantha* & Fabaceae & 0 & 0 & 1 & 1 & 0 & 0 & 1 & 1 & 3 & 2 & 0,95 & 0,917 & 3 & 2 & 0,95 & 0,972 & & & Ane & \\
\hline 45 Psychotria spp* & Rubiaceae & 2 & 2 & 0,95 & 0,917 & 0 & 0 & 1 & 1 & 0 & 0 & 1 & 1 & 2 & 2 & 0,95 & 0,972 & & & $\mathrm{Z}$ & \\
\hline 46 Pterocarpus rohri & Fabaceae & 1 & 1 & 0,975 & 0,917 & 1 & 1 & 0,975 & 0,917 & 0 & 0 & 1 & 1 & 2 & 2 & 0,95 & 0,944 & 0,1 & 0,0937 & Ane & 20 \\
\hline 47 Swartzia/Erythrina* & Fabaceae & 0 & 0 & 1 & 1 & 4 & 2 & 0,95 & 0,917 & 0 & 0 & 1 & 1 & 4 & 2 & 0,95 & 0,972 & & & Ane & \\
\hline 48 Aparisthmium cordatum $®$ & Euphorbiaceae & 0 & 0 & 1 & 1 & 0 & 0 & 1 & 1 & 157 & 1 & 0,975 & 0,667 & 157 & 1 & 0,975 & 0,889 & 0,125 & 0,029 & Auto & 10 \\
\hline 49 Cariniana $\mathrm{sp}^{*}$ & Lecythidaceae & 1 & 1 & 0,975 & 0,917 & 0 & 0 & 1 & 1 & 0 & 0 & 1 & 1 & 1 & 1 & 0,975 & 0,972 & & & Ane & \\
\hline 50 Cordia cf. ecalyculata* & Boraginaceae & 1 & 1 & 0,975 & 0,917 & 0 & 0 & 1 & 1 & 0 & 0 & 1 & 1 & 1 & 1 & 0,975 & 0,972 & & & $\mathrm{Z}$ & \\
\hline 51 Eriotheca pentaphylla & Malvaceae & 1 & 1 & 0,975 & 0,917 & 0 & 0 & 1 & 1 & 0 & 0 & 1 & 1 & 1 & 1 & 0,975 & 0,972 & 0,425 & 0,5767 & Auto & 18 \\
\hline 52 Eugenia $\mathrm{sp} 1$ & Myrtaceae & 0 & 0 & 1 & 1 & 0 & 0 & 1 & 1 & 1 & 1 & 0,975 & 0,917 & 1 & 1 & 0,975 & 0,972 & & & $\mathrm{Z}$ & \\
\hline 53 Eugenia $\mathrm{sp} 2$ & Myrtaceae & 1 & 1 & 0,975 & 0,917 & 0 & 0 & 1 & 1 & 0 & 0 & 1 & 1 & 1 & 1 & 0,975 & 0,972 & & & $\mathrm{Z}$ & \\
\hline
\end{tabular}




\begin{tabular}{|c|c|c|c|c|c|c|c|c|c|c|c|c|c|c|c|c|c|c|c|c|c|}
\hline \multirow{2}{*}{ Espécie } & \multirow{2}{*}{ Família } & \multicolumn{4}{|c|}{ Ano 1} & \multicolumn{4}{|c|}{ Ano 2} & \multicolumn{4}{|c|}{ Ano 3} & \multicolumn{4}{|c|}{ Total } & \multirow{2}{*}{$\mathbf{F}$} & \multirow{2}{*}{$\mathbf{M}$} & \multirow{2}{*}{ SD } & \multirow{2}{*}{ HL } \\
\hline & & $\mathbf{A B}$ & $\mathrm{NC}$ & LDE & LDT & $\mathbf{A B}$ & NC & LDE & LDT & $\mathbf{A B}$ & NC & LDE & LDT & $\mathbf{A B}$ & $\mathrm{NC}$ & LDE & LDT & & & & \\
\hline 54 Eugenia $\mathrm{sp} 3$ & Myrtaceae & 0 & 0 & 1 & 1 & 1 & 1 & 0,975 & 0,917 & 0 & 0 & 1 & 1 & 1 & 1 & 0,975 & 0,972 & & & $\mathrm{Z}$ & \\
\hline 55 Eugenia sp4 & Myrtaceae & 2 & 1 & 0,975 & 0,917 & 0 & 0 & 1 & 1 & 0 & 0 & 1 & 1 & 2 & 1 & 0,975 & 0,972 & & & $\mathrm{Z}$ & \\
\hline 56 Eugenia sp5 & Myrtaceae & 1 & 1 & 0,975 & 0,917 & 0 & 0 & 1 & 1 & 0 & 0 & 1 & 1 & 1 & 1 & 0,975 & 0,972 & & & $\mathrm{Z}$ & \\
\hline 57 Eugenia sp6 & Myrtaceae & 1 & 1 & 0,975 & 0,917 & 0 & 0 & 1 & 1 & 0 & 0 & 1 & 1 & 1 & 1 & 0,975 & 0,972 & & & $\mathrm{Z}$ & \\
\hline 58 Eugenia $\mathrm{sp} 7$ & Myrtaceae & 0 & 0 & 1 & 1 & 0 & 0 & 1 & 1 & 1 & 1 & 0,975 & 0,917 & 1 & 1 & 0,975 & 0,972 & & & Z & \\
\hline 59 Eugenia sp9 & Myrtaceae & 0 & 0 & 1 & 1 & 1 & 1 & 0,975 & 0,917 & 0 & 0 & 1 & 1 & 1 & 1 & 0,975 & 0,972 & & & $\mathrm{Z}$ & \\
\hline 60 Eugenia melanogyna & Myrtaceae & 0 & 0 & 1 & 1 & 1 & 1 & 0,975 & 0,917 & 0 & 0 & 1 & 1 & 1 & 1 & 0,975 & 0,972 & & & $\mathrm{Z}$ & \\
\hline 61 Ficus sp1 & Moraceae & 2 & 1 & 0,975 & 0,917 & 0 & 0 & 1 & 1 & 0 & 0 & 1 & 1 & 2 & 1 & 0,975 & 0,972 & & & $\mathrm{Z}$ & \\
\hline 62 Ficus insipida & Moraceae & 0 & 0 & 1 & 1 & 0 & 0 & 1 & 1 & 2 & 1 & 0,975 & 0,917 & 2 & 1 & 0,975 & 0,972 & 0,025 & 0,0024 & $\mathrm{Z}$ & 4 \\
\hline 63 Geonoma sp & Arecaceae & 1 & 1 & 0,975 & 0,917 & 0 & 0 & 1 & 1 & 0 & 0 & 1 & 1 & 1 & 1 & 0,975 & 0,972 & & & $\mathrm{Z}$ & \\
\hline 64 Jacaranda puberula & Bignoniaceae & 0 & 0 & 1 & 1 & 0 & 0 & 1 & 1 & 1 & 1 & 0,975 & 0,917 & 1 & 1 & 0,975 & 0,972 & 0,275 & 0,0075 & Ane & 15 \\
\hline 65 Mabea piriri & Euphorbiaceae & 0 & 0 & 1 & 1 & 0 & 0 & 1 & 1 & 1 & 1 & 0,975 & 0,917 & 1 & 1 & 0,975 & 0,972 & 0,025 & 0,1027 & Auto & 16 \\
\hline 66 Machaerium nyctitans & Fabaceae & 0 & 0 & 1 & 1 & 0 & 0 & 1 & 1 & 1 & 1 & 0,975 & 0,917 & 1 & 1 & 0,975 & 0,972 & 0,025 & 0,1601 & Ane & 15 \\
\hline 68 Marlierea tomentosa ${ }^{\circledR}$ & Myrtaceae & 3 & 1 & 0,975 & 0,833 & 10 & 1 & 0,975 & 0,833 & 0 & 0 & 1 & 1 & 13 & 1 & 0,975 & 0,889 & 0,125 & 0,5136 & $\mathrm{Z}$ & 8 \\
\hline 69 Myrcia sp2 & Myrtaceae & 0 & 0 & 1 & 1 & 1 & 1 & 0,975 & 0,917 & 0 & 0 & 1 & 1 & 1 & 1 & 0,975 & 0,972 & & & $\mathrm{Z}$ & \\
\hline 70 Myrcia sp3 & Myrtaceae & 0 & 0 & 1 & 1 & 1 & 1 & 0,975 & 0,917 & 0 & 0 & 1 & 1 & 1 & 1 & 0,975 & 0,972 & & & $\mathrm{Z}$ & \\
\hline 71 Myrcia pubipetala ${ }^{\circledR}$ & Myrtaceae & 0 & 0 & 1 & 1 & 0 & 0 & 1 & 1 & 5 & 1 & 0,975 & 0,917 & 5 & 1 & 0,975 & 0,972 & 0,3 & 0,0704 & $\mathrm{Z}$ & 16 \\
\hline 72 Myrcia racemosa & Myrtaceae & 0 & 0 & 1 & 1 & 3 & 1 & 0,975 & 0,917 & 0 & 0 & 1 & 1 & 3 & 1 & 0,975 & 0,972 & 0,575 & 0,0598 & $\mathrm{Z}$ & 10 \\
\hline 73 Ocotea aciphylla & Lauraceae & 0 & 0 & 1 & 1 & 1 & 1 & 0,975 & 0,917 & 0 & 0 & 1 & 1 & 1 & 1 & 0,975 & 0,972 & 0,1 & 2.142 & $\mathrm{Z}$ & 16 \\
\hline 74 Ocotea brachybotrya* & Lauraceae & 1 & 1 & 0,975 & 0,917 & 0 & 0 & 1 & 1 & 0 & 0 & 1 & 1 & 1 & 1 & 0,975 & 0,972 & & & $\mathrm{Z}$ & \\
\hline 75 Oreopanax capitatus & Araliaceae & 0 & 0 & 1 & 1 & 0 & 0 & 1 & 1 & 1 & 1 & 0,975 & 0,917 & 1 & 1 & 0,975 & 0,972 & 0,025 & 0,024 & $\mathrm{Z}$ & 12 \\
\hline 76 Posoqueria latifolia & Rubiaceae & 1 & 1 & 0,975 & 0,917 & 0 & 0 & 1 & 1 & 0 & 0 & 1 & 1 & 1 & 1 & 0,975 & 0,972 & 0,275 & 0,1798 & $\mathrm{Z}$ & 12 \\
\hline 77 Sapotaceae & Sapotaceae & 1 & 1 & 0,975 & 0,917 & 0 & 0 & 1 & 1 & 0 & 0 & 1 & 1 & 1 & 1 & 0,975 & 0,972 & & & $\mathrm{Z}$ & \\
\hline 78 Schizolobium parahiba* & Fabaceae & 0 & 0 & 1 & 1 & 1 & 1 & 0,975 & 0,917 & 0 & 0 & 1 & 1 & 1 & 1 & 0,975 & 0,972 & & & Ane & \\
\hline 79 Strychnus brasiliensis* & Loganiaceae & 0 & 0 & 1 & 1 & 0 & 0 & 1 & 1 & 1 & 1 & 0,975 & 0,917 & 1 & 1 & 0,975 & 0,972 & & & $\mathrm{Z}$ & \\
\hline 80 Tachigali denudata* & Fabaceae & 0 & 0 & 1 & 1 & 0 & 0 & 1 & 1 & 3 & 1 & 0,975 & 0,917 & 3 & 1 & 0,975 & 0,972 & & & Ane & \\
\hline 81 Terminalia sp* & Combretaceae & 4 & 1 & 0,975 & 0,833 & 2 & 1 & 0,975 & 0,833 & 0 & 0 & 1 & 1 & 6 & 1 & 0,975 & 0,889 & & & Ane & \\
\hline
\end{tabular}


Anexo 3

Espécies arbóreas encontradas na chuva de sementes em cada um dos 36 meses do estudo. As espécies estão em ordem de decrescente de acordo com o número de coletores em que foram encontradas nos três anos de estudo (ANEXO 2).

* Espécies encontradas na chuva de sementes que não foram amostradas no levantamento arbóreo.

Espécies

\begin{tabular}{llllllllllllllllllllllllllllllllllll} 
Out & Nov & Dez & Jan & Fev & Mar & Abr & Mai & Jun & Jul & Ago & Set & Out & Nov & Dez & Jan & Fev & Mar & Abr & Mai & Jun & Jul & Ago & Set & Out & Nov & Dez & Jan & Fev & Mar & Abr & Mai & Jun & Jul & Ago & Set \\
\hline
\end{tabular}

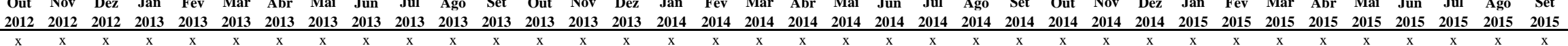
2 Myrsine spp.

3 Alchornea triplinervia

5 Nectandra oppositifolia

6 Cecropia spp.

7 Hymenolobi

$m$ janeiren.

9 Pera glabra

10 Geonoma schottiana

11 Inga sp.

12 Cupania/Matayba*

13 Laplacea fruticosa

14 Maprounea guianensis

15 Myrcia sp.4

17 Amalopha intermedia

18 Matayba intermedia

19 Ocotea pulchella

20 Guapira spp.

21 Guarea macrophylla

22 Hyeronima alchorneoides

23 Anaxagorea dolichocarpa

24 Guatteria australis

25 Heisteria silvianii

26 Sloanea guianensis

27 Dictyoloma vandellianum *

29 Handroanthus/Tabebuid
30 Lauraceae

30 Lauraceae

31 Prunus myrtifolia
32 Solanum spp.*

33 Diospyros brasiliensis

34 Eugenia cerasiflora

35 Marlierea sp.

36 Myrcia sp. 1

37 Myrcia multiflora

38 Stylogyne lhotzkyana

39 Calyptranthes sp.

40 Daphnopsis sp

41 Eugenia sp.8
42 Inga sessilis

43 Manilkara subsericea

44 Piptadenia gonoacantha

45 Psychotria spp.*

46 Pterocarpus rohri

47 Swartzia/Erythrina*

48 Aparisthmium cordatum

49 Cariniana sp."

50 Cordia cf. ecalyculata *

51 Eriotheca pentaphylla

52 Eugenia sp.1 
Espécies $\begin{array}{lllllllllllllllllllllllllllllllllllllll}\text { Out Nov } & \text { Dez } & \text { Jan } & \text { Fev } & \text { Mar } & \text { Abr } & \text { Mai } & \text { Jun } & \text { Jul } & \text { Ago } & \text { Set } & \text { Out } & \text { Nov } & \text { Dez } & \text { Jan } & \text { Fev } & \text { Mar } & \text { Abr } & \text { Mai } & \text { Jun } & \text { Jul } & \text { Ago } & \text { Set } & \text { Out } & \text { Nov } & \text { Dez } & \text { Jan } & \text { Fev } & \text { Mar } & \text { Abr } & \text { Mai } & \text { Jun } & \text { Jul } & \text { Ago } & \text { Set }\end{array}$ $\frac{\text { Espécies }}{53 \text { Eugenia sp.2 }}$ 54 Eugenia sp. 3 55 Eugenia sp.4

56 Eugenia sp. 5

57 Eugenia sp. 6
58 Eugenia $\mathrm{sp} 7$

58 Eugenia sp.7

60 Eugenia melanogyna

61 Ficus sp.1

62 Ficus insipida

63 Geonoma sp.

64 Jacaranda puberula

65 Mabea piriri

66 Machaerium nyctitan

67 Marlierea racemosa

68 Marlierea tomeria sp.2
70 Myrcia sp. 3

70 Myrcia sp.3
71 Myrcia pubipetala
72 Myrcia racemosa

73 Ocotea aciphylla

74 Ocotea brachybotrya*

75 Oreopanax capitatus

76 Posoqueria latifolia

77 Sapotaceae

78 Schizolobium parahiba*

79 Strychnus brasiliensis

81 Terminalia sp.*

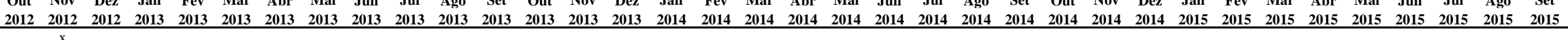

82 Ficus spp.

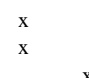

(1)

$x$




\section{Anexo 4}

Relação entre as variáveis resposta (Limitação de dispersão espacial e Limitação de dispersão temporal) e os fatores fixos testados por meio da abordagem de seleção de modelos mistos. A = LDe $\sim$ Frequência, $\mathrm{B}=\mathrm{LDe} \sim$ Altura, $\mathrm{C}=\mathrm{LDe} \sim$ Massa, $\mathrm{D}=\mathrm{LDe} \sim$ Síndromes de dispersão, E $=\mathrm{LDt} \sim \mathrm{Frequência,} \mathrm{F}=\mathrm{LDt}$ Altura, G: LDt Massa, H: LDt Síndromes de dispersão. Os pontos correspondem a 93 observações referentes a 31 espécies em 3 anos.
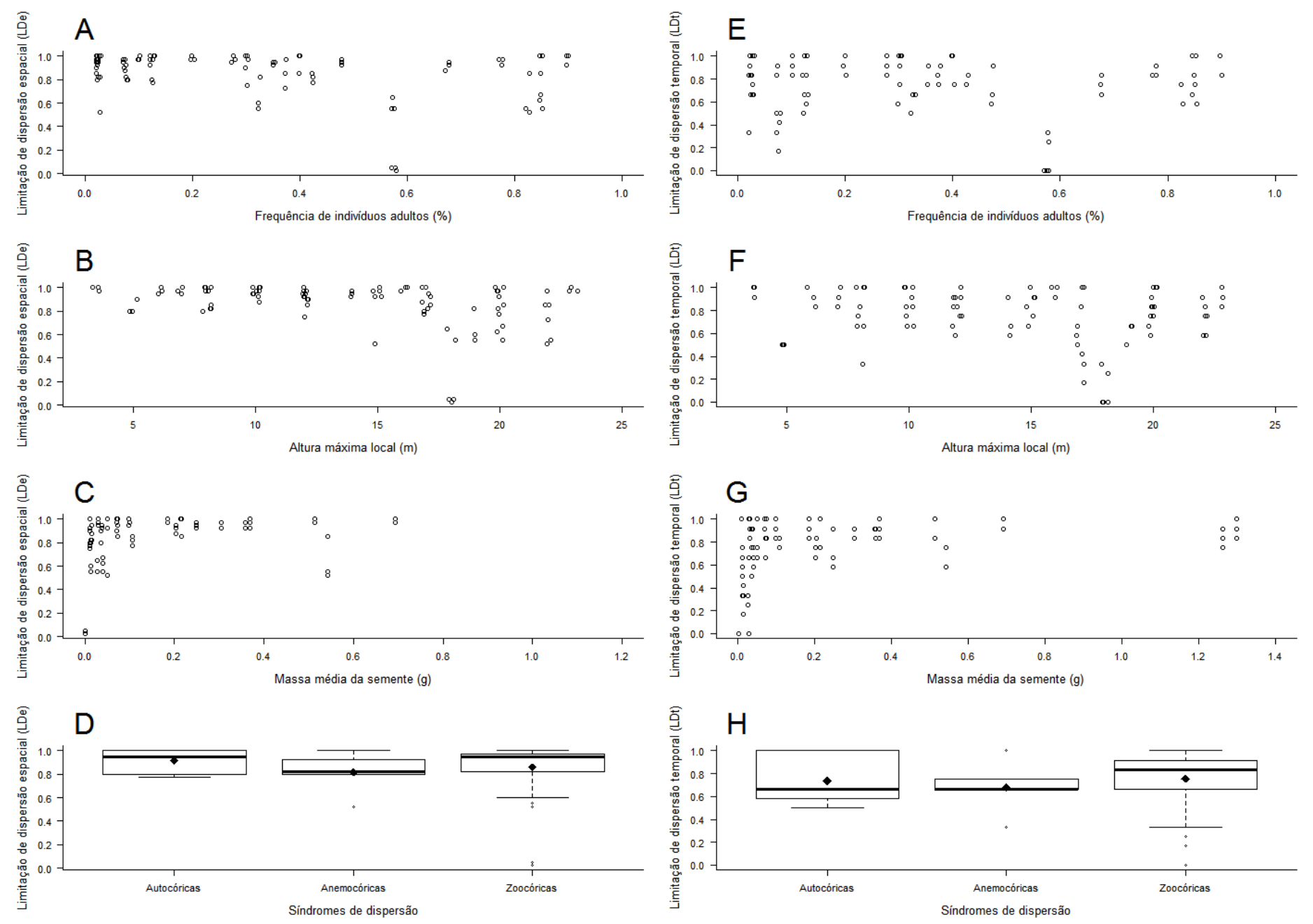


\section{Anexo 5}

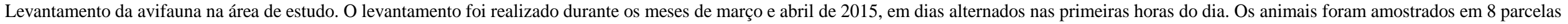
do levantamento arbóreo. O tempo permanecido em cada parcela foi de $20 \mathrm{~min}$ e, nesse tempo, era tomado nota da presença das espécies por meio de registros visuais e sonoros. Nas colunas estão indicadas o número de vezes que o animal foi amostrado e entre parênteses está o total de amostras na parcela.

Espécie

\section{Amazilia fimbriata}

Amazilia lactea

Amazilia versicolor

Amazona aestiva

Amazona farinosa

Anabacerthia lichtensteini

Aramides saracura

Attila rufus

Brotogeris tirica

Camptostoma obsoletum

Cantorchilus longirostris

Caracara plancus

Celeus flavescens

Chaetura meridionalis

Chamaeza campanisona

Chiroxiphia caudata

Cichlocolaptes leucophrus

Cnemotriccus fuscatus

Colaptes campestris

Columbina talpacoti

Conopophaga melanops

Coereba flaveola

Crotophaga ani

Crypturellus obsoletus

Dendrocincla turdina

Dysithamnus mentalis

Euphonia chlorotica

Euphonia pectoralis

Euphonia violaced

Florisuga fusca

Formicarius colma

Furnarius rufu

Gnorimopsar chopi

Guira guira

Habia rubica

Hemitriccus orbitatus

Herpetotheres cachinnan
Família

Trochilidae

Trochilidae

Trochilidae

Psittacidae

Psittacidae

Furnariidae

Rallidae

Tyrannidae

Psittacidae

Tyrannidae

Troglodytidae

Falconidae

Picidae

Apodidae

Formicariidae

Pipridae

Furnariidae

Tyrannidae

Picidae

Columbidae

Conopophagidae

Thraupidae

Cuculidae

Tinamidae

Dendrocolaptidae

Thamnophilidae

Fringillidae

Fringillidae

Fringillidae

Trochilidae

Formicariidae

Furnariidae

Icteridae

Cuculidae

Cardinalidae

Rhynchocyclidae

Falconidae
Grupo funcional

Nectarívoro

Nectarívoro

Nectarívoro

Frugívoro

Frugívoro

Insetívoro

Onívoro

Insetívoro

Frugívoro

Insetívoro

Onívoro

Onívoro

Insetívoro

Insetívoro

Insetívoro e sementes

Frugívoro (dispersor)

Insetívoro

Insetívoro

Insetívoro

Granívoro e Frugívoro (dispersor) Insetívoro

Nectarívoro e frugívoro

Carnívoro

Sementes

Insetívoro

Insetívoro

Frugívoro (dispersor)

Frugívoro (dispersor)

Frugívoro (dispersor)

Nectarívoro

Insetívoro

insetívoro

Onívoro

Carnívoro

Frugívoro e insetívoro (dispersor)

Insetívoro

Onívoro

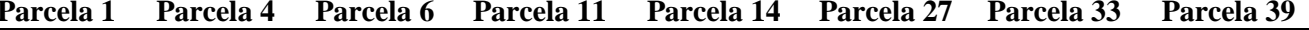
$1(7)$

$1(7)$

$1(7) \quad 2(7)$

4(7) $\quad 2(7)$

2(7)

2(7)

$1(7)$

$3(7)$

2(6)

1(7) $\quad 1(7) \quad 3(6)$

3(7)

7(7)

$5(7)$

5(7)

6(6)

$5(7)$

1(7)

1(7)

1(6)

2(7)

1(7)

1(7)

1(7)

1(7)

4(7)

2(7)

(7)

3(7)

4(7)

1(7)

$1(7)$

$3(7)$

2(7)

1(7)

2(7)

1(7)

2(7)

$1(7)$

4(7)

$$
\begin{aligned}
& 3(6) \\
& 2(6)
\end{aligned}
$$

1(7)

1(7)

1(7)

1(7)

1(7)

2(7) $\quad 4(7)$

1(7) 2(7)

2(7) $1(7)$

1(7) $3(7)$

3(6)

1(7)

1(7)

1(7)

2(7) 
Espécie

Família

Herpsilochmus rufimarginatus Thamnophilidae

Heterospizia (conferir)

Heterospizia meridionalis

Hypoedaleus guttatus

Lathrotriccus euleri

Leptopogon amaurocephalus

Manacus manacus

Megaceryle torquato

Melanerpes candidus

Milvago chimachima

Myiozetetes similis

Myrmotherula unicolor

Não identificado

Patagioenas picazuro

Phaethornis squalidus

Philydor atricapillus

Piaya cayana

Piculus flavigula

Picumnus sp.

Picumnus temminckii

Pionopsitta pileata

Pionus maximiliani

Pitangus sulphuratus

Platyrinchus mystaceus

Progne chalybea

Progne tapera

Pygochelidon cyanoleuca

Pyriglena leucoptera

Pyrrhura frontalis

Ramphastos toco

Ramphocelus bresilius

Ramphodon naevius

Rupornis magnirostris

Schiffornis virescens

Setophaga pitiayumi

Sporophila frontalis

Sturnella superciliaris

Tachyphonus coronatus

Tangara palmarum

Tangara sayaca

Tangara seledon

Thalurania glaucopis

Todirostrum poliocephalum

Accipitridae

Thamnophilidae

Tyrannidae

Rhynchocyclidae

Pipridae

Alcedinidae

Picidae

Falconidae

Tyrannidae

Thamnophilidae

Columbidae

Trochilidae

Furnariidae

Cuculidae

Picidae

Picidae

Picidae

Psittacidae

Psittacidae

Tyrannidae

Platyrinchidae

Hirundinidae

Hirundinidae

Hirundinidae

Thamnophilidae

Psittacidae

Ramphastidae

Thraupidae

Trochilidae

Accipitridae

Tityridae

Parulidae

Thraupidae

Icteridae

Thraupidae

Thraupidae

Thraupidae

Thraupidae

Trochilidae
Grupo funcional

Insetívoro

Rhynchocyclidae

Carnívoro

Insetívoro

Insetívoro

Insetívoro

Frugívoro (dispersor)

Carnívoro

Insetívoro

Onívoro

Insetívoro

Insetívoro

Insetívoro

Insetívoro

Insetívoro

Insetívoro

Frugívoro

Frugívoro

Generalista

Insetívoro

Entomófago

Entomófago

Entomófago

Insetívoro

Frugívoro

Onívoro (dispersor)

Frugívoro (dispersor)

$$
\text { Nectarívoro }
$$

Carnívoro

Insetívoro

Granívoro

Insetívoro

Frugívoro (dispersor)

Frugívoro (dispersor)

Nectarívoro

Insetívoro

Parcela 1 $\begin{array}{lllllll}\text { Parcela 4 } & \text { Parcela 6 } & \text { Parcela 11 } & \text { Parcela 14 } & \text { Parcela 27 } & \text { Parcela 33 } & \text { Parcela 39 }\end{array}$

$\begin{array}{llllllll}4(7) & 3(7) & 6(7) & 4(6) & 1(7) & 7(7) & 6(7) & 4(6)\end{array}$

Insetívoro (frugívoro no inverno - dispersor)

$\begin{array}{cc}\text { Frugívoro e granívoro (dispersor) } & 2(7) \\ \text { Nectarívoro } & 1(7)\end{array}$

$1(7)$

$1(7)$

1(7)

$3(7)$

$1(7)$

Frugívoro e insetívoro (dispersor)

$1(6)$

$1(7)$

1(7) $1(7)$

1(6)

1(7)

1(7)

1(7)

4(6)

1(7)

1(7)

2(7)

3(6)

$1(7)$

1(7) $\quad 1(6)$

$1(7) \quad 4(6)$

1(6)

1(7)

1(7)

$1(7)$

2(6)

1(6)

3(7)

$1(7)$

2(7)

1(7)

5(7)

1(7)

1(7)

1(7)

$\begin{array}{ll}3(7) & 1(7) \\ & 3(7)\end{array}$

1(6)

2(6)

2(6)

3(7)

2(7)

3(7)

1(7)

2(7)

1(7)

1(7)

1(7)

4(7)

4(7)

3(7)

$6(7)$
$5(7)$

1(6)

2(7)

3(7)

$5(7)$

3(7)

1(7)

$3(7)$

1(7)

3(7)

4(7)

$6(7)$

$2(7)$
$1(7)$

1(7)

5(6)

1(7)

2(7)

Frugívoro (dispersor)

Frugívoro (dispersor)
1(7)

3(7)

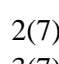

3(7)

1(7)

1(7)

1(7)

1(7)

$3(7)$
$1(7)$
$1(7)$
$1(7)$

$3(7)$
$1(7)$
$1(7)$
$1(7)$

$6(6)$
$1(6)$
$2(6)$
$1(6)$

$1(6)$
$1(6)$
2(7)

$1(7)$

3(7)

$6(7)$

1(7)

1(7)

2(7)

(7)

1(7)

1(6) 
Tolmomyias sulphurescens Rhynchocyclidae

Insetívoro

Troglodytidae

Insetívoro

4(7)

Trogonidae

Insetívoro e frugívoro (dispersor)

Trogon viridis

Turdus amaurochalinus

Trogonidae

Insetívoro e Frugívoro (dispersor)

Frugívoro (dispersor)
Frugívoro (dispersor)

Turdidae

Turdidae

Frugívoro (dispersor)

Tyrannidae

Insetívoro (frugívoro no inverno - dispersor)

Carnívoro

Insetívoro

Insetívoro

Xenopidae

Insetívoro

2(7)

1(7)

2(6)

1(6)

Tyrannus melancholicus

Xenops minutus

Xiphorhynchus fuscus
1(7)

1(6)

1(7)

1(7)

2(7)

3(7) $\quad 3(7)$

$3(7)$
$3(7)$

1(7)

1(7)
1(7)

3(7)

1(7)
1(7) $\quad 3(7)$

2(7)

1(7)

3(7) 